This PDF is a selection from a published volume from the National Bureau of Economic Research

Volume Title: Measuring Wealth and Financial Intermediation and Their Links to the Real Economy

Volume Author/Editor: Charles R. Hulten and Marshall B. Reinsdorf, editors

Series: Studies in Income and Wealth, volume 73

Volume Publisher: University of Chicago Press

Volume ISBN: 0-226-20426-X, 978-0-226-20426-0 (cloth); 978-0-226-20443-7 (eISBN)

Volume URL: http://www.nber.org/books/hult10-1

Conference Date: November 12-13, 2010

Publication Date: January 2015

Chapter Title: Household Debt and Saving during the 2007 Recession

Chapter Author(s): Rajashri Chakrabarti, Donghoon Lee, Wilbert van der Klaauw, Basit Zafar

Chapter URL: http://www.nber.org/chapters/c12525

Chapter pages in book: (p. $273-322)$ 


\title{
Household Debt and Saving during the 2007 Recession
}

\author{
Rajashri Chakrabarti, Donghoon Lee, \\ Wilbert van der Klaauw, and Basit Zafar
}

\subsection{Introduction}

During the 2007 recession many households saw their wealth decline sharply and their income and employment opportunities deteriorate. In this chapter we use microeconomic data to analyze changes in household financial decisions during this period and, in particular, changes in household saving and debt. More specifically, we focus on the following three questions: What is the nature and prevalence of financial distress and how does it vary across households? How have households responded to these new economic conditions? What are consumers' expectations about future economic outcomes and their future financial behaviors?

Our analysis in this chapter is based on several unique data sources. First, the Federal Reserve Bank of New York (FRBNY) Consumer Credit Panel, which is based on credit report records, provides detailed insights into developments on the liability side of household balance sheets since 1999. Second, we use information on household financial decisions and expectations, such as on spending and saving, from several recent household surveys. We analyze survey evidence collected between November 2008 and February 2009

Rajashri Chakrabarti is a senior economist at the Federal Reserve Bank of New York. Donghoon Lee is a senior economist at the Federal Reserve Bank of New York. Wilbert van der Klaauw is a senior vice president at the Federal Reserve Bank of New York. Basit Zafar is a senior economist at the Federal Reserve Bank of New York.

The views expressed are those of the authors and do not necessarily reflect those of the Federal Reserve Bank of New York. We have benefitted from helpful comments from Andrew Haughwout, Meta Brown, and Joseph Tracy. Maricar Mabutas provided excellent research assistance. For acknowledgments, sources of research support, and disclosure of the authors' material financial relationships, if any, please see http://www.nber.org/chapters/c12525.ack. 
by RAND to assess the impact of the financial crisis. ${ }^{1}$ In addition, and of particular importance for this study, we analyze data we collected ourselves through a special survey on saving, administered between the end of October 2009 and January 2010 as part of the Household Inflation Expectations Project. ${ }^{2}$ Both the RAND and NYFed surveys were administered as part of the RAND American Life Panel (ALP), an Internet-based survey. Brief descriptions of the ALP and the FRBNY Consumer Credit Panel are provided in the appendix. We also verified some of our findings using data from the Consumer Finance Monthly (CFM), a monthly telephone survey conducted by Ohio State University since 2005 .

We begin in section 9.2 with an analysis of the extent and nature of the impact of the financial and economic crisis on households. We focus on four main channels, distinguishing between changes in the housing market, stock market, labor market, and credit market. In section 9.3 we evaluate the different ways in which households have responded to these changes in their economic environment. We then assess individuals' expectations regarding future conditions and behavior in section 9.4 , and provide a brief summary in section 9.5 .

\subsection{The Nature and Prevalence of Financial Distress during the Recession}

\subsubsection{The Housing Market}

Perhaps the most defining aspect of the 2007 recession, and considered by many to be the origin of the financial crisis, has been the decline in the housing market. As shown in figure 9.1, since reaching a peak in April 2007, by the end of 2009 US house prices as measured by the FHFA home price index had fallen 13 percent nationwide. ${ }^{3}$ This overall decrease masks considerable variation across states and metropolitan areas. For example, average prices dropped by 39 percent and 38 percent, respectively, from their peaks in California and Florida, while average home prices fell by 4 percent in Colorado and increased by 1 percent in Texas.

The large increase in home prices until 2007 (an increase of 44 percent from 2002 levels) and the decline since then implies that home value losses experienced by consumers depend greatly on when a home was purchased. Overall, in nominal terms, only for those who bought their homes in 2005 or later is the average value of their home currently lower than what they paid

1. The RAND survey module was designed by Mike Hurd and Susann Rohwedder. Detailed discussions of related and additional findings from this survey, as well as a number of follow-up surveys, are provided in Hurd and Rohwedder (2010).

2. For further information about the Household Inflation Expectations Project, see Bruine de Bruin et al. (2010).

3. Other indices, such as the CoreLogic HPI and S\&P/Case-Shiller HPIs showed even larger average declines of up to 30 percent during this period. 


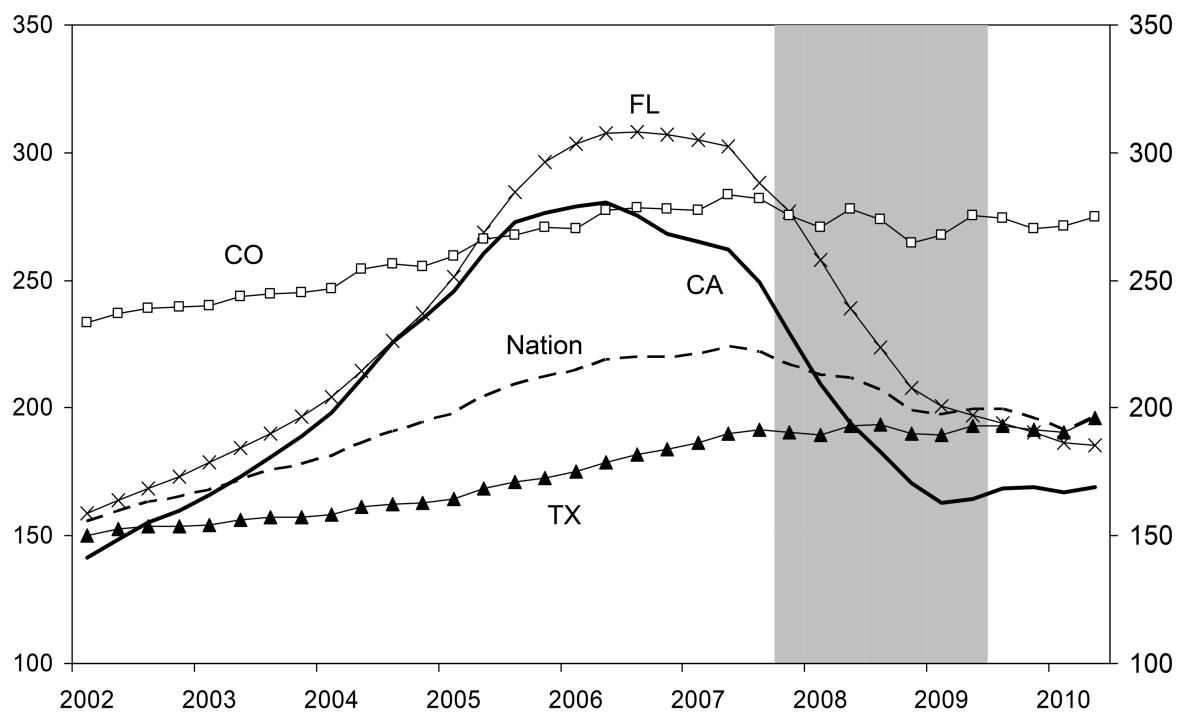

Fig. 9.1 FHFA home price trends

Source: FHFA.

Note: FHFA HPI-purchase only (NSA, quarterly).

for it. As shown in figure 9.2, those who experienced the greatest losses in nominal terms were those who bought their homes in 2007. The average loss by the beginning of 2010, as measured by the FHFA home price index, was a little over 10 percent for this group. Interestingly, the average self-reported change in house value for this group was only about 6 percent in the NYFed survey. This is consistent with earlier findings in the literature suggesting that individual perceptions of home price changes generally are more optimistic than suggested by official numbers. ${ }^{4}$

An important consequence of the initial increase and subsequent fall in average house prices for households, not conveyed in figure 9.2, is the dramatic fall in home equity. As shown in figure 9.3, with the rise in home prices total equity of homeowners rose. However, it did so at a much lower rate with homeowners' equity share in their homes actually staying relatively constant until the end of 2006. On average, for each 1 percent increase in home prices, homeowners increased their mortgage debt by 1 percent (through higher balances on first mortgages, cash-out refinances, second mortgages, and home equity lines of credit), so that proportionally their equity share in their

4. Note that those individuals who bought their homes in 2009 perceived on average that their homes had increased in value by 6.5 percent at the end of 2009 (although the median reported change was 0 percent). 


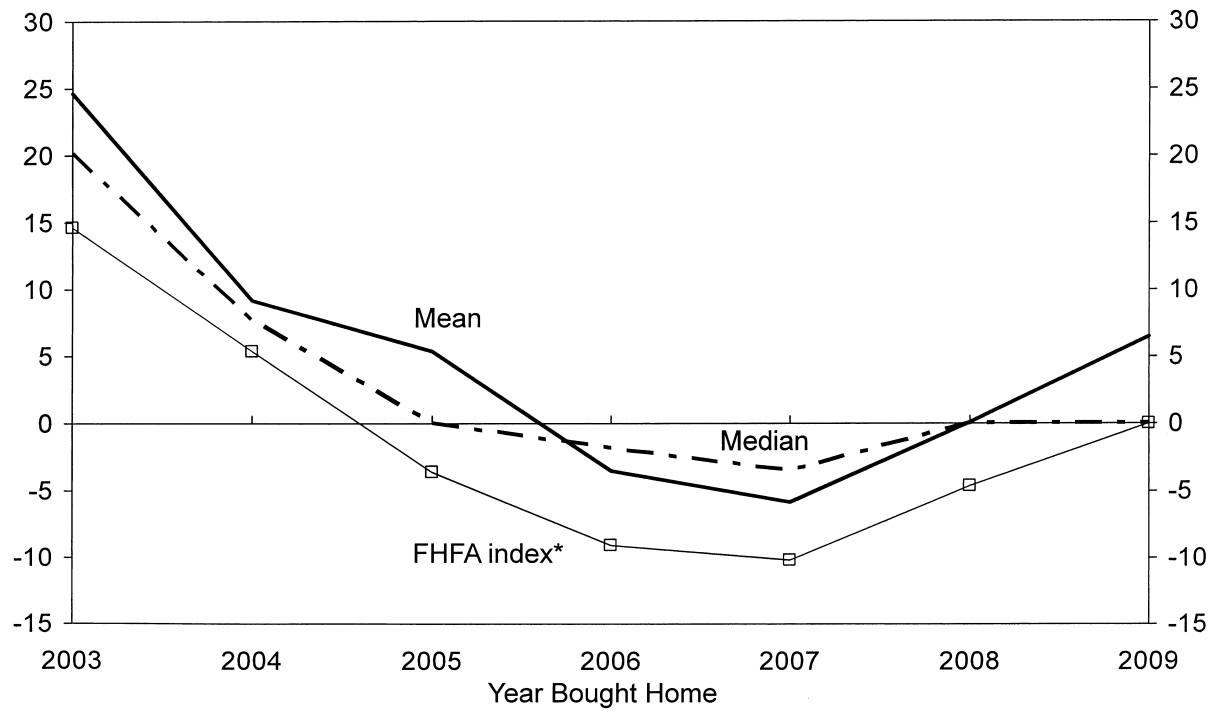

Fig. 9.2 Self-reported home value change since time bought

Source: NYFed survey.

*FHFA HPI-purchase only (NSA, annual).

Trillions of Dollars

Percent

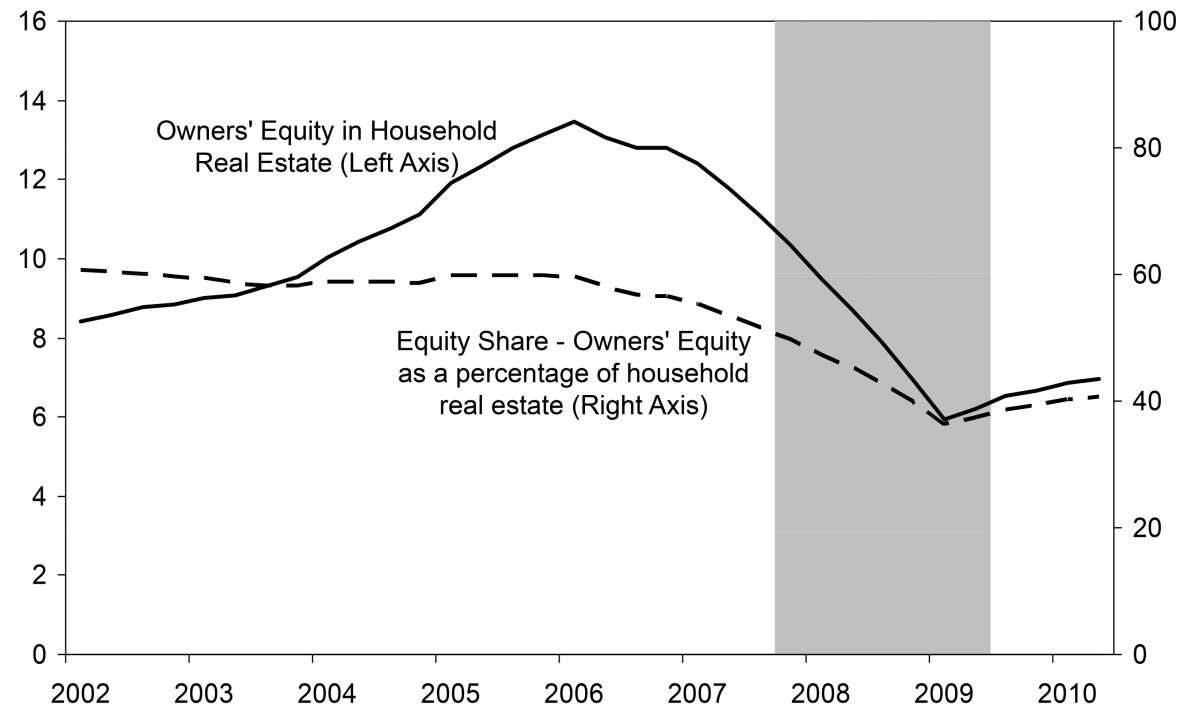

Fig. 9.3 Trends in owners' equity

Source: FHFA. 


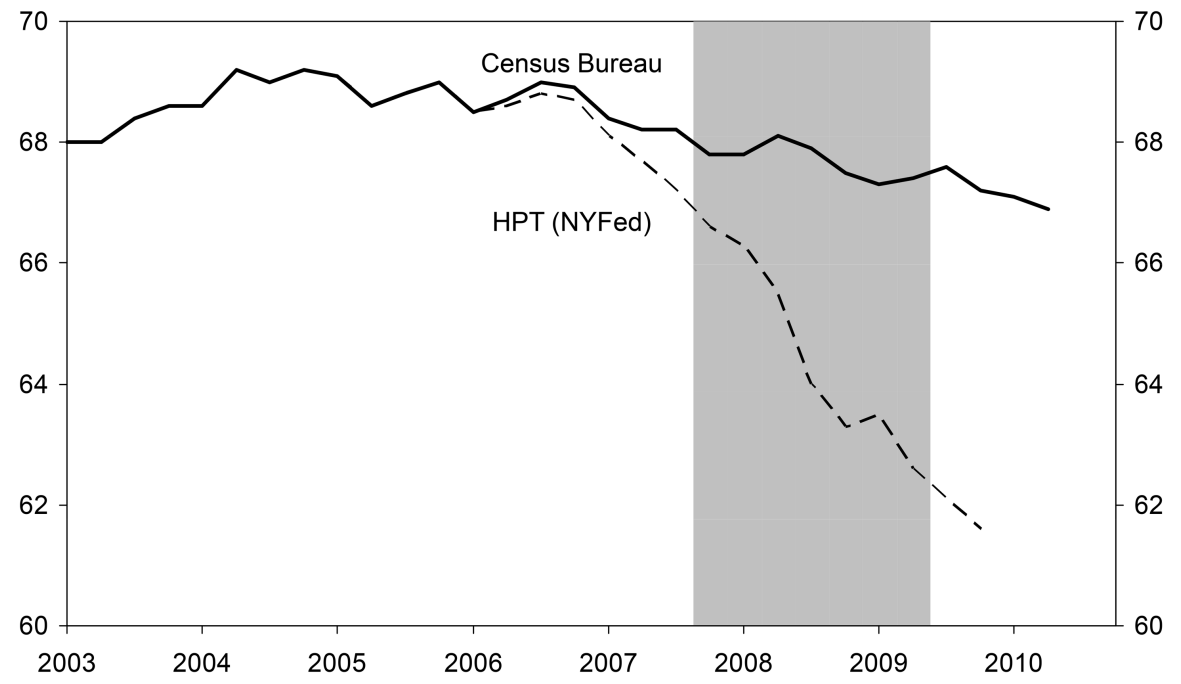

Fig. 9.4 Homeownership rates

Source: US homeownership rate (NSA), Census Bureau. Effective homeownership rate as in Haughwout, Peach, and Tracy (2010).

homes actually remained constant. When home prices began to fall in 2007, owners' equity in household real estate began to fall rapidly from almost \$13.5 trillion in 1Q 2006 to a little under \$5.3 trillion in 1Q 2009, a decline in total home equity of over 60 percent. At the end of 2009 owners' equity was estimated at $\$ 6.3$ trillion, still more than 50 percent below its 2006 peak.

With the loss in home equity, a growing proportion of homeowners in fact lost all equity in their homes, finding the mortgage debt on their property to exceed its current market value. While the decline in house prices was accompanied by a small decline in the overall home ownership rate, ${ }^{5}$ the "effective homeownership rate" as defined in Haughwout, Peach, and Tracy (2010) as the proportion of individuals with a positive amount of home equity, fell since 2007 by more than 7 percentage points (figure 9.4). ${ }^{6}$

Exposure to declines in housing values varied not only geographically, but also across different age and income groups. As shown in table 9.1, ownership rates during the survey period (November 2009-January 2010)

5. After reaching a peak in 2004, by early 2010 the homeownership rate in the United States had declined by almost 2 percentage points from around 69 percent to 67 percent. The decline was greatest among younger age groups, varying from 3 percent for those younger than 35 , 4 percent for those age 35-45, 3 percent for those ages 45-55, and a little over 1 percent for those over 65 (Census Bureau, homeownership by age of householder, not seasonally adjusted [NSA]).

6. See Haughwout, Peach, and Tracy (2010). 


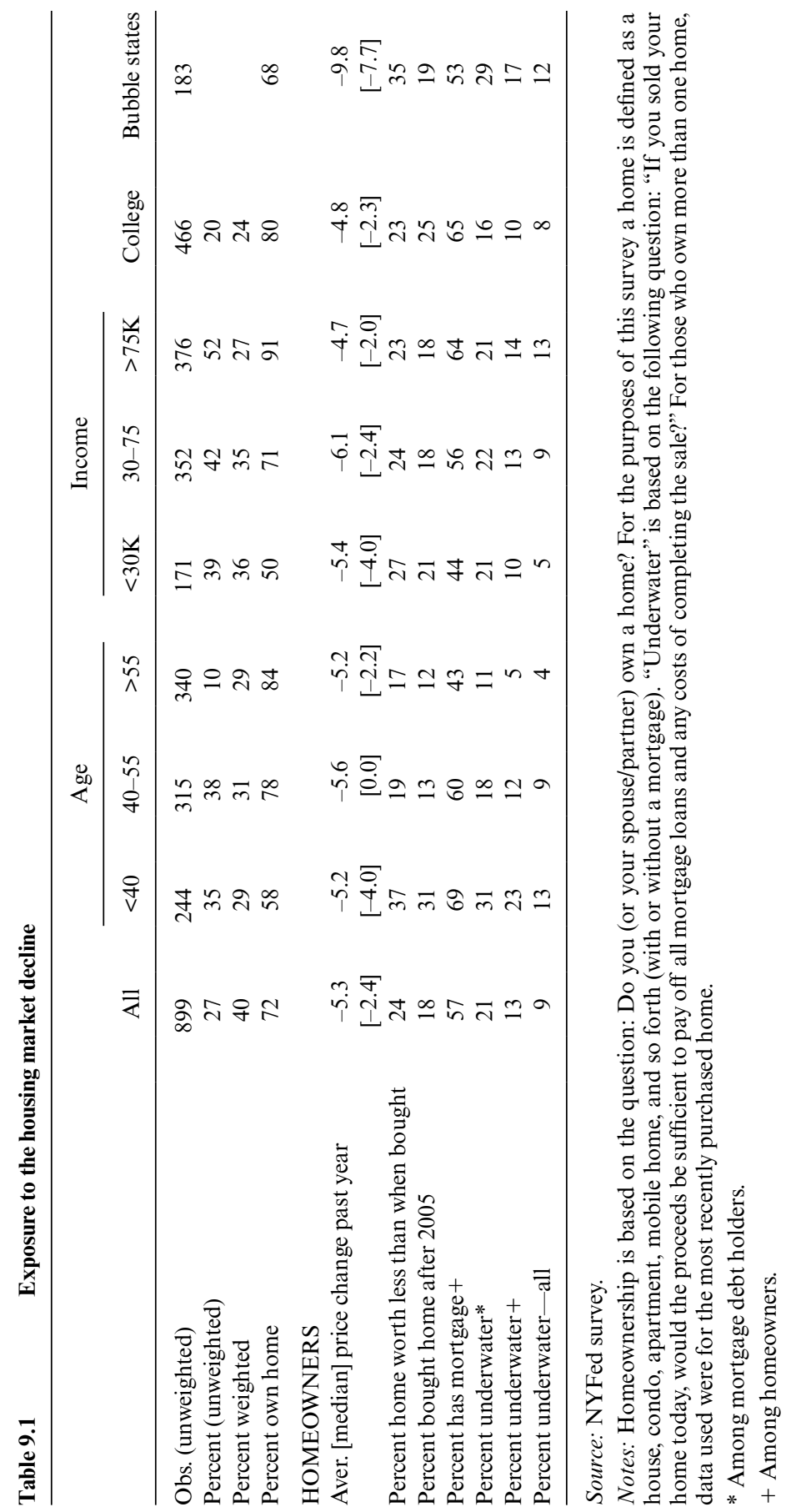


varied from 58 percent for those under 40, to 78 percent among those age $40-55$, and 84 percent for those older than $55 .{ }^{7}$ Homeownership rates also increased monotonically with household income, with 50 percent of those with incomes under $\$ 30,000$ owning a home, while 91 percent did so among those earning more than $\$ 75,000$. The homeownership rate among college graduates was 80 percent, while in what we refer to as the "bubble states," the five states that experienced the largest housing booms and/or busts, the rate was 68 percent, slightly below the overall sample mean of 72 percent. $^{8}$

As shown in table 9.1, the average and median perceived price declines during the year preceding the interview date varied little by age, education, and income, but were considerably larger in the bubble states, in which prices during the past year were believed to have fallen on average by almost 10 percent. Similarly, the proportion of people who perceived the current value of their home to be lower than what they paid for it was 35 percent in the bubble states, whereas for the country as a whole it was 24 percent. The rate was also higher among homeowners under age forty and those with incomes under $\$ 30,000$, of whom a much higher proportion bought their homes after 2005 .

Reflecting a greater share of homeowners who have paid off their mortgages, the proportion of owners who have an outstanding balance on their mortgage is much lower among older individuals. Among homeowners with mortgages at the end of 2009, 21 percent reported to be "underwater" at the time of the survey, with the fraction being the highest among those under age forty ( 31 percent) and those living in the bubble states ( 29 percent). ${ }^{9}$ As shown in table 9.2, these higher proportions of individuals who report to be underwater on their mortgages partly reflect a greater share of homeowners who bought their homes after 2005. However, it also reflects how much equity was taken out by owners during the housing boom, with the proportion with negative equity being much larger among those with higher mortgage debt. Finally, the share of mortgage holders underwater is much higher among investors, defined here as those with three or more first mortgages. This is consistent with ongoing research based on the FRBNY Consumer Credit Panel, showing that while historically lower, delinquency rates among this group has recently been much higher than that for noninvestors.

In summary, the direct impact of the housing crisis has been confined to homeowners, who are on average somewhat older and have higher incomes

7. All survey statistics (for NYFed and RAND samples) presented in this chapter are calculated using sample weights based on population statistics calculated from the 2009 CPS March Supplement survey (see appendix).

8. The "bubble states" include Arizona, California, Florida, Michigan, and Nevada.

9. A homeowner is defined to be underwater if they answered no to the question "If you sold your home today, would the proceeds be sufficient to pay off all mortgage loans and any costs of completing the sale?" The overall rate of 21 percent is comparable to that computed by First American CoreLogic, which reported that more than 11.3 million, or 24 percent, of all residential properties with mortgages were in negative equity at the end of the fourth quarter of 2009 (First American CoreLogic Q4 2009 Negative Equity Report, 2010). 
Table 9.2

Characteristics of mortgage debt holders

\begin{tabular}{lcc}
\hline & $\begin{array}{c}\text { Percent of mortgage } \\
\text { holders above water who }\end{array}$ & $\begin{array}{c}\text { Percent of mortgage } \\
\text { holders } \text { underwater who }\end{array}$ \\
\hline Bought home after 2005 & 16 & 29 \\
Have mortgage debt $<100 \mathrm{~K}$ & 58 & 35 \\
Have mortgage debt $(100 \mathrm{~K}$, 200K) & 29 & 34 \\
Have mortgage debt $>200 \mathrm{~K}$ & 13 & 31 \\
Own 1-2 homes & 98 & 94 \\
Own 3+ homes & 2 & 6 \\
\hline
\end{tabular}

Source: NYFed survey.

Notes: Mortgage debt is based on the question: "Do you (or your spouse/partner) have any outstanding loans against the value of your home(s), including all mortgages, home equity loans, and home equity lines of credit? If yes: Which category represents the total amount of current outstanding loans against your home(s) (Less than $\$ 25,000, \$ 25,000$ to $\$ 49,999$, $\$ 50,000$ to $\$ 99,999, \$ 100,000$ to $\$ 149,999, \$ 150,000$ to $\$ 199,999, \$ 200,000$ to $\$ 299,999$, $\$ 300,000$ to $\$ 499,999, \$ 500,000$ to $\$ 799,999$, or $\$ 800,000$ or more)?"

than renters. Among owners, many saw considerable gains in housing wealth evaporate during the recession, with those who bought their homes after 2005 (on average younger and with lower incomes) and those living in one of the bubble states experiencing the largest nominal losses and most likely to currently be underwater on their mortgage. Ultimately, the impact of the decline in the housing market on a specific household's financial situation and behavior will depend on many factors, including where the house is located, when the house was bought, how it was financed, how much equity was extracted during the housing boom, the owner's ability to make mortgage payments, and on how long the household plans to live in the home.

\subsubsection{The Stock Market}

In addition to significant losses in housing wealth during the 2007 recession, many households experienced considerable losses in their stock market wealth following the stock market crash in October 2008. As measured by the S\&P 500 index, after falling more than 45 percent between the end of 2007 and the beginning of 2009, the stock market has rebounded somewhat, but stocks at the end of 2009 remained approximately 27 percent below their peak values (figure 9.5).

Not all households were directly affected by this drop in stock values, with exposure varying considerably across households. Based on the 2007 Survey of Consumer Finances, stock market participation rates, as measured by the proportion of families holding stocks directly or indirectly (through mutual funds in pension accounts), increases monotonically with income from less than 14 percent for those in the bottom income quintile to 91 percent in the top decile (table 9.3). A similar positive relationship with income is found for the average and median stock value held by stock market participants. The 


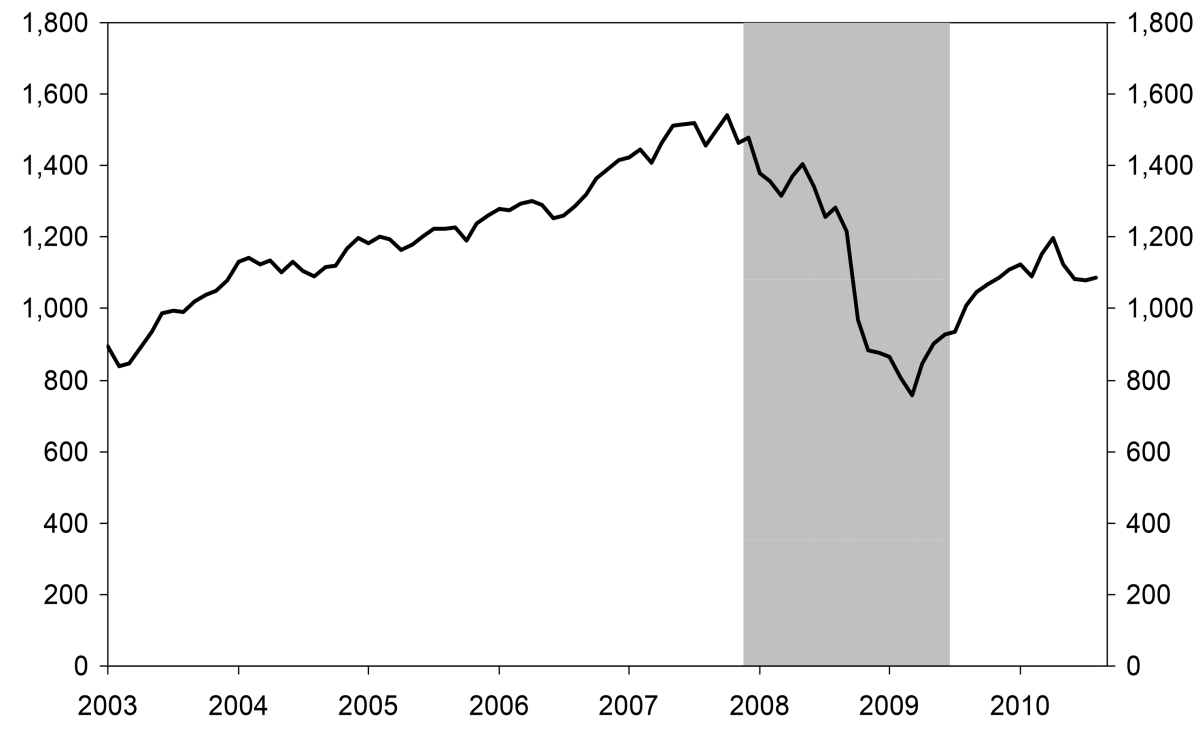

Fig. 9.5 S\&P 500 stock market trend

Table 9.3 Stock market participation in 2007

Families having stock Median value among families with holdings, direct or indirect holdings (thousands of 2007 dollars)

\begin{tabular}{llr}
\hline All families & 51.1 & 35.0 \\
$\begin{array}{l}\text { Percentile of income } \\
\text { Less than 20 }\end{array}$ & 13.6 & 6.5 \\
$20-39.9$ & 34.0 & 8.8 \\
$40-59.9$ & 49.5 & 17.7 \\
$60-79.9$ & 70.5 & 34.1 \\
$80-89.9$ & 84.4 & 62.0 \\
$90-100$ & 91.0 & 219.0 \\
Age of head (years) & & \\
Less than 35 & 38.6 & 7.0 \\
35-44 & 53.5 & 26.0 \\
$45-54$ & 60.4 & 45.0 \\
55-64 & 58.9 & 78.0 \\
65-74 & 52.1 & 57.0 \\
75 or more & 40.1 & 41.0 \\
Housing status & & \\
Owner & 62.5 & 41.2 \\
Renter & 26.0 & 8.6 \\
\hline
\end{tabular}

Source: Survey of Consumer Finances 2007. See Bucks, Kennickell, Mach, and Moore (2009). 
participation rate, as well as the median stock value held among participants, has a bell-shaped relationship with respect to the age of the household head. Reflecting a lower average income, stock market exposure was also much lower on average for renters.

The same patterns exhibited by the 2007 Survey of Consumer Finances also show up in responses to the 2008 RAND survey shown in table 9.4. In November 2008, 58 percent of households reported to directly or indirectly own stocks at a median value of $\$ 40,000$. Approximately 90 percent of stockholders reported a loss in the overall value of their stocks since October 1, 2008, with 38 percent reporting losses over 30 percent. Both rates show very little variation across demographic groups. During a period in which, on average, the S\&P 500 index fell by 24 percent, those reporting positive stock holdings reported a median 25 percent decline in stock value between October 1, 2008, and the interview date in November 2008, corresponding to a median loss in value of $\$ 12,000 .{ }^{10}$ Some 38 percent of stockholders reported losses of over 30 percent. While there was little variation in percentage losses across demographic groups, a percentage loss of 25 percent translates into very different dollar values, varying between $\$ 4,000$ for stockholders under age forty and those with lower incomes (incomes under $\$ 30,000)$, and $\$ 25,000$ for stockholders over fifty-five and with high incomes (incomes over $\$ 75,000$ ).

The patterns for stock ownership found in the RAND survey are consistent with those for pension plan participation in the NYFed survey. Older individuals and higher-income individuals are twice as likely (about 50 percent versus 25 percent) to report that they or their spouse currently are, or ever have been enrolled in a defined-benefit pension plan. Similarly, 86 percent of individuals with household incomes over $\$ 75,000$ report that they or their spouse currently are or ever have been enrolled in a defined-contribution plan (such as a 401[k], individual retirement account [IRA], tax-deferred annuity or 403[b], 457 thrift savings plan), while only 38 percent reported so for individuals with incomes under $\$ 30,000$. Across age groups we find an inverted-U pattern, with 56 percent of individuals under age forty having such a pension plan, 78 percent of individuals between age forty and fifty-five, and 65 percent of individuals older than fifty-five ever or currently participating in such a plan. Thus the decline in the stock market is most likely to have affected middle- and older-age individuals and those with higher household incomes.

\subsubsection{The Labor Market}

Since the recession began, the unemployment rate increased by more than 5 percentage points to 10 percent at the end of 2009 , while the proportion of

10. Averaged over all the daily closings during November 2008, the S\&P500 had fallen, on average, by 24 percent since October 1, 2008. 


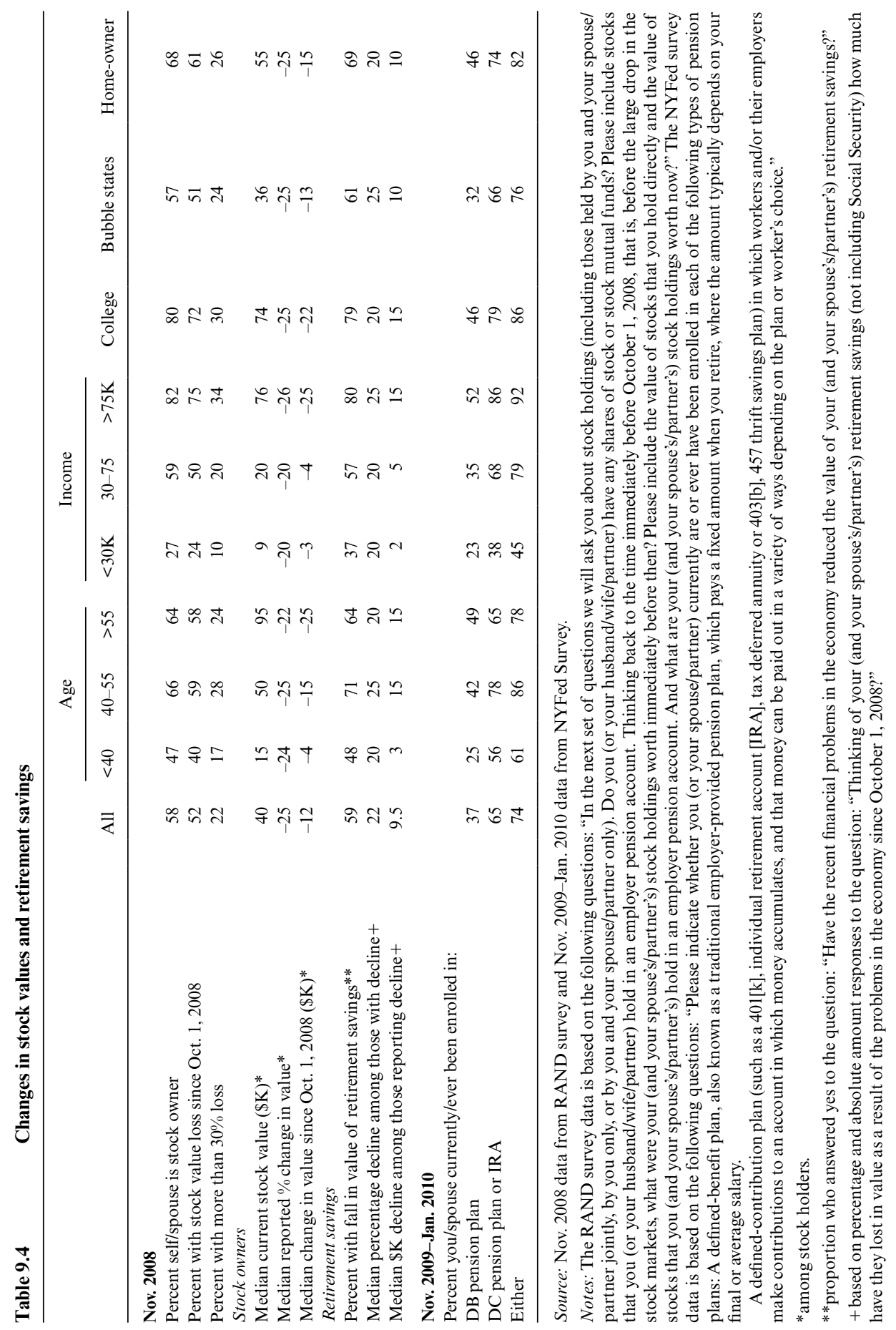




\section{Percent}

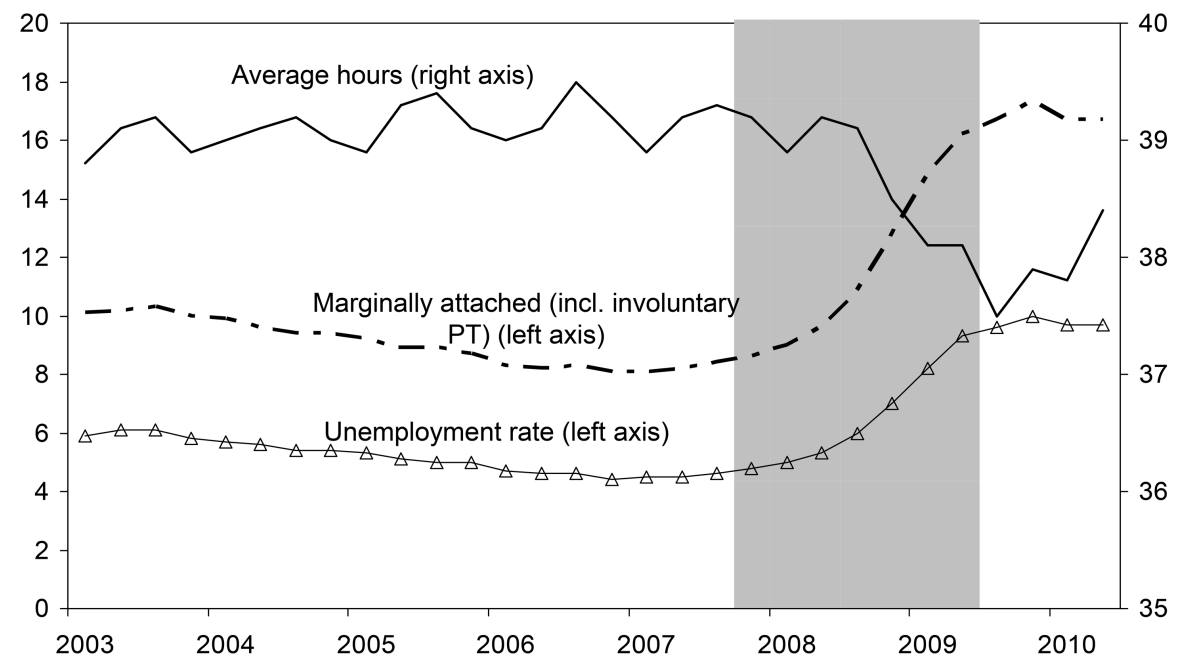

Fig. 9.6 Unemployment rate, proportion marginally attached, and average weekly hours

Source: BLS.

those marginally attached to the labor force (which includes the unemployed as well as those involuntarily working part-time) increased from about 8 percent in 2007 to 17 percent at the end of 2009. As shown in figure 9.6, during the past two years there also was a considerable fall in the average weekly hours of work.

Not surprisingly, these patterns are reflected in the trends for personal income, calculated by the National Income and Product Accounts. As shown in figure 9.7, between the end of 2007 and the end of 2009 per capita real personal income fell by 3.8 percent, with total compensation and wages falling respectively by 5.8 percent and 6.7 percent during this period. However, as also shown in the figure, per capita disposable income remained relatively constant during this period, due to a drop in personal taxes.

Not all households were equally affected by the decline in the labor market. As shown in table 9.5, unemployment rates as reported in the NYFed survey at the end of 2009 varied considerably by age and geography, with younger individuals and those living in the bubble states more likely to be unemployed at the time of the survey. ${ }^{11}$ Not surprisingly, unemployment was

11. The lower overall unemployment rate of 7 percent in the NYFed sample compared to a national rate closer to 10 percent at the end of 2009 may be due to a difference between what individuals believe constitutes being unemployed and how unemployment is officially measured. It may also reflect a lower survey response rate among the unemployed. 


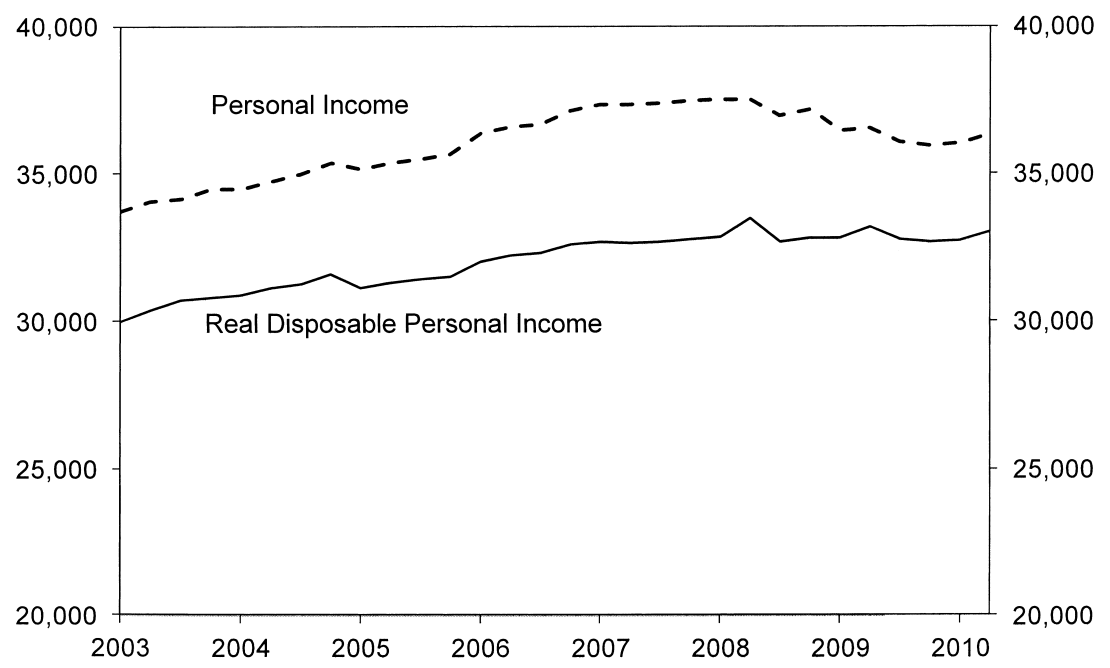

Fig. 9.7 Personal income

Source: BEA, SAAR, in 2005 dollars.

also more prevalent in (and a cause of) lower income households. The same patterns are found for spousal unemployment -8 percent of respondents report a job loss by a spouse during the past twelve months. During the survey period, in 14 percent of households either the respondent was currently unemployed and/or had a spouse who had been laid off during the past year. In addition to losing jobs, significant proportions of respondents reported incurring a pay cut (15 percent), having to take unpaid furlough days off (7 percent), losing 401(k) matching (8 percent), and reductions in health benefits (14 percent) during the last twelve months. Homeowners, individuals over age fifty-five, and those with household incomes over $\$ 75,000$ were less likely to report pay cuts or reductions in health benefits.

As reported in table 9.5, the combined impact of employment losses and wage cuts led to an overall average decrease in pretax household income of about 3.9 percent during 2009, with 19 percent of individuals reporting losses of 10 percent of income or higher. While all demographic groups suffered income losses during the past year, the losses were greatest among the forty to fifty-five age group (average decline of 5.8 percent) and among individuals living in bubble states ( 4.7 percent).

\subsubsection{Credit Markets}

During a recession in which most interest rates on personal loans fell, the most significant change in the credit markets was an overall decline in 


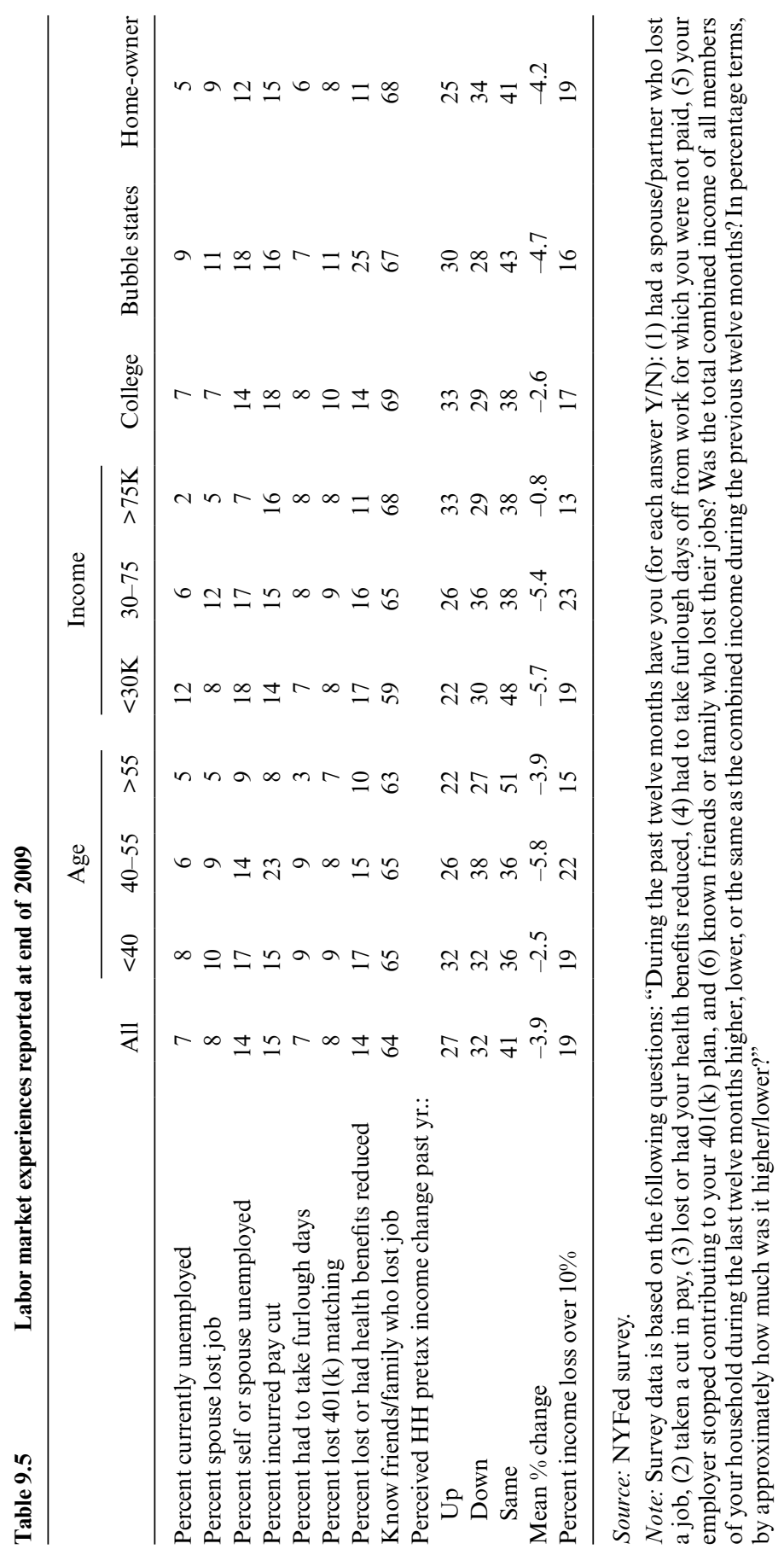




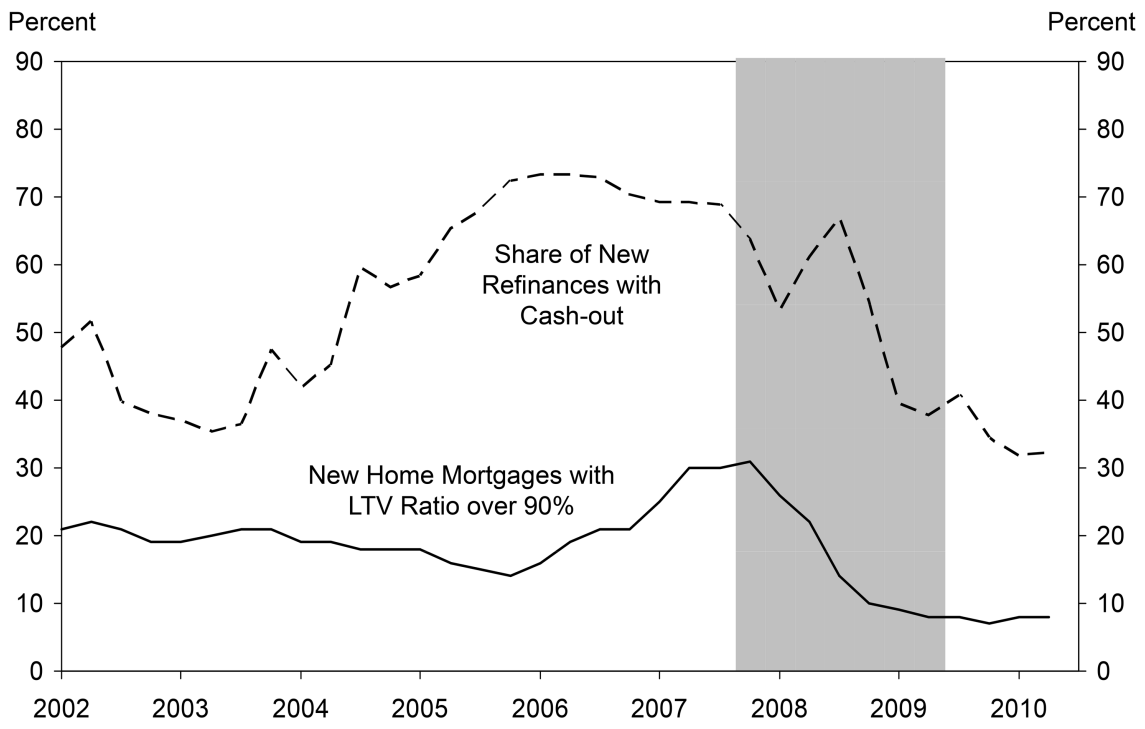

Fig. 9.8 Consumer credit-Mortgage LTVs and cash-outs Source: FHFA.

demand for and a tightening in the supply of credit. ${ }^{12}$ As shown in figure 9.8, reflecting an overall sharp decline in the average loan-to-value ratio of new mortgage loans, the proportion of all mortgage originations with loan/ price ratios over 90 percent dropped steadily from 31 percent in the middle of 2007 to about 7 percent of new mortgages at the end of $2009 .{ }^{13}$ At the same time, the proportion of refinances involving a cash-out dropped dramatically from over 70 percent of refinances in early 2006 to 35 percent of refinances at the end of 2009. ${ }^{14}$

Another striking change during the past year has been a decline in the number of loan accounts opened and a sharp increase in the number of accounts closed. As shown in figure 9.9, the FRBNY Consumer Credit Panel indicates that about 319 million accounts were closed during 2009, while just 166 million were opened. Credit cards have been the primary source of these reductions: the number of open credit card accounts fell to 394 million by

12. At the end of 2009, while average rates on credit cards were comparable to those at the end of 2007, interest rates on fixed-rate thirty-year mortgage loans, forty-eight-month new car loans, and twenty-four-month personal loans had, on average, all fallen by a little over 1 percentage point since the end of 2007.

13. After a gradual increase in the average loan-to-value ratio on all mortgage loans, which came to a halt at the end of 2007, by the end of 2009 it had fallen back to 73.9 percent, a level not seen since early 2004 (FHFA).

14. During the same period, total cash-out dollars as a proportion of aggregate refinanced originations dropped from about 30 percent to 6 percent (FHFA). 


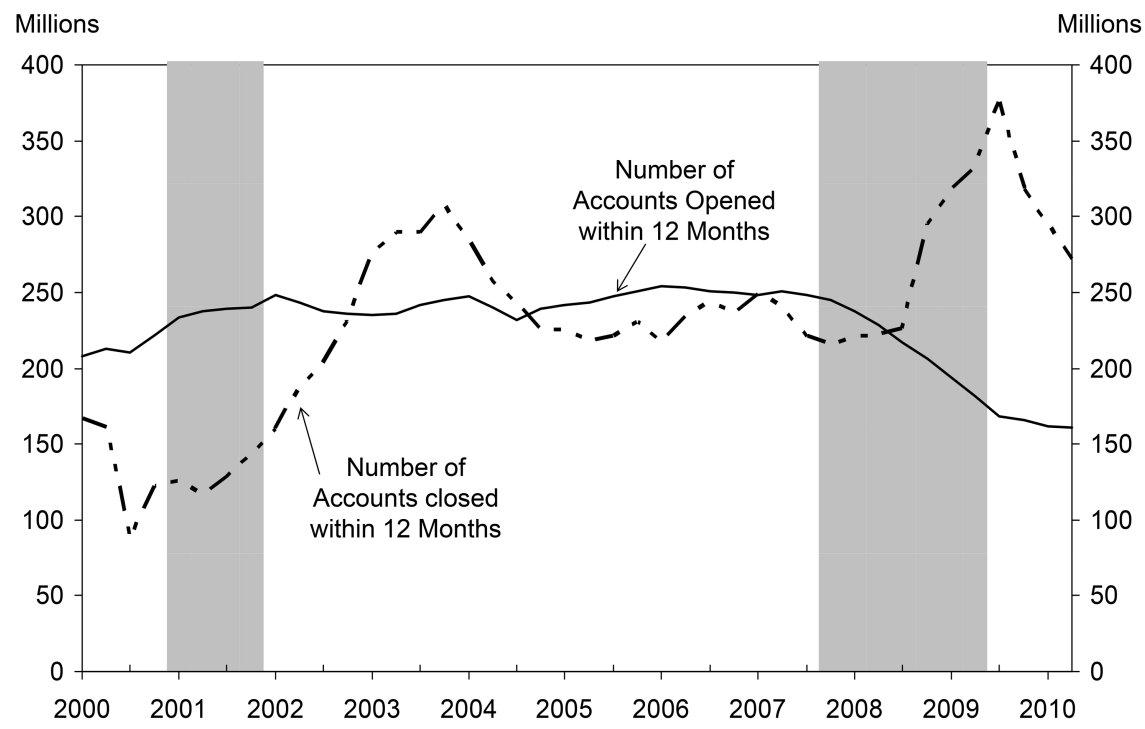

Fig. 9.9 Total number of new and closed accounts

Source: FRBNY Consumer Credit Panel.

the end of December 2009, a decrease of 78 million (16.5 percent) from a year earlier and 20.5 percent from the peak in 2008:Q2.

Additional insight into the apparent tightening of credit and closing of accounts is provided in table 9.6. During the survey period at the end of 2009,57 percent of respondents perceived that it had become more difficult to obtain credit compared to a year earlier, while only 12 percent thought it had become easier. Little variation shows up in these responses across age and income groups. While 36 percent of respondents reported to have closed a credit card account during the past year at their own request, 13 percent reported to have had one of their credit card accounts closed by the bank or credit card company, with the proportion being highest among younger and lower-income respondents and among those living in one of the bubble states. ${ }^{15}$

Finally, approximately equal proportions of respondents reported increases and decreases in the combined total credit limit on their combined credit cards. Decreases were more prevalent for the highest income group and those living in bubble states, while they were less prevalent among the lowest income group (for whom credit limits are likely to have been low to

15. Additional survey data collected by the FRBNY between December 2009 and January 2010 indicated that about twice as many credit card accounts were closed at the customer's request than were closed at the banks' initiative. Of all cards closed (at own request or not), 43 percent had a zero balance at the time of closing. 


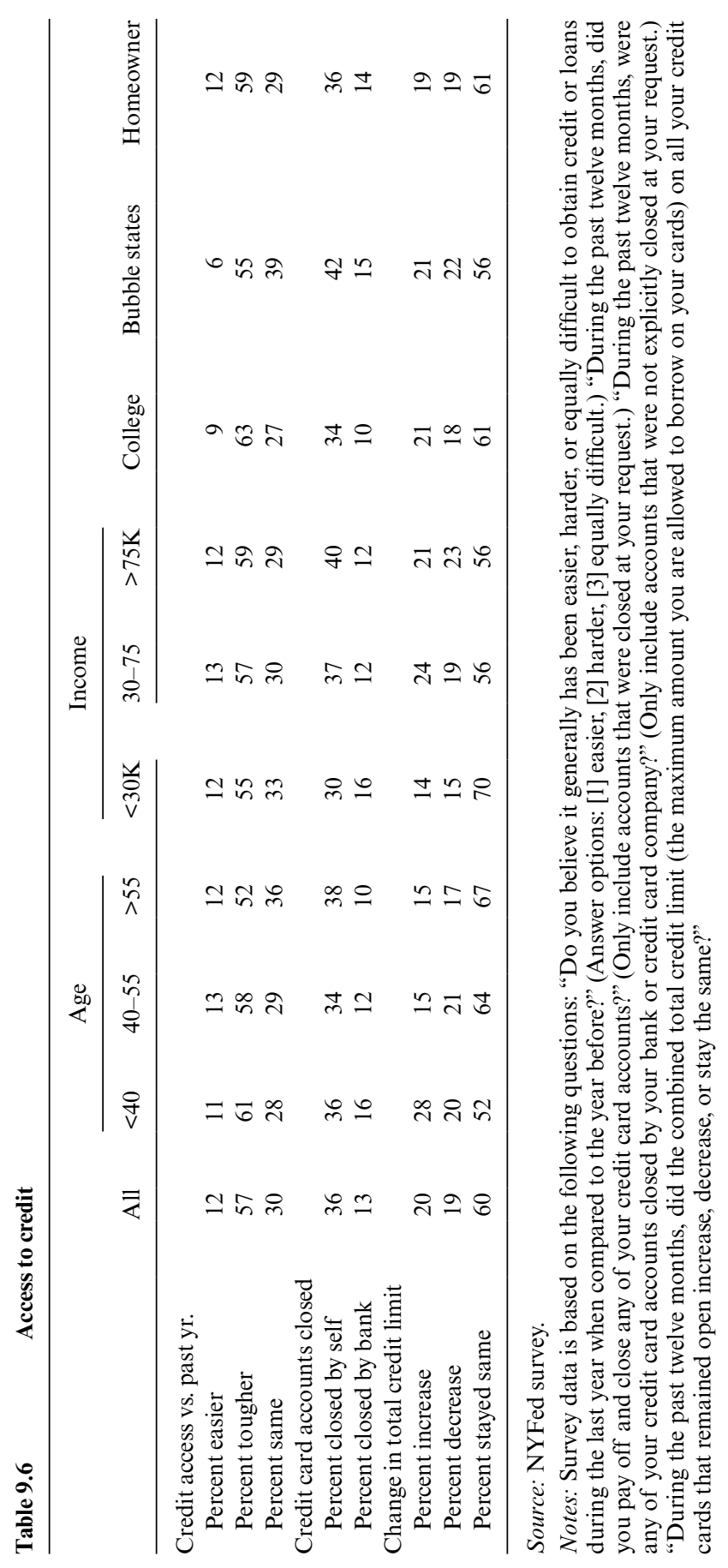


begin with). Increases in credit limits were instead more likely to be reported by those under age forty and with incomes in the $\$ 30,000-\$ 75,000$ range.

\subsubsection{Measures of Overall Distress}

The reported microeconomic evidence of considerable declines in housing and stock market wealth is consistent with the large drop in per capita net worth calculated by the Flow of Funds Accounts and shown in figure 9.10. Given the decline in net worth as well as the weak labor market, it is not surprising that since the middle of 2008 a majority of respondents in the Reuters/University of Michigan Survey of Consumers considered themselves to be worse off financially than a year earlier. During the past year only about 20 percent report that they (and their family) are better off financially than they were a year ago (figure 9.11). When differentiating by age (not shown), we find these trends to apply equally to all age groups, except that overall ratings of changes in one's personal financial situation are persistently somewhat higher (less negative) for younger and lower (more negative) for older individuals.

As shown in table 9.7, about 68 percent of consumers in the RAND survey reported in November 2008 that they had been affected "somewhat" or "a lot" by the crisis. The proportion of individuals who reported to have been affected a lot, was greatest among the forty to fifty-five age group and among individuals living in one of the housing crisis states. In the November 2008 survey, a little under half of the respondents reported to be worse off finan-

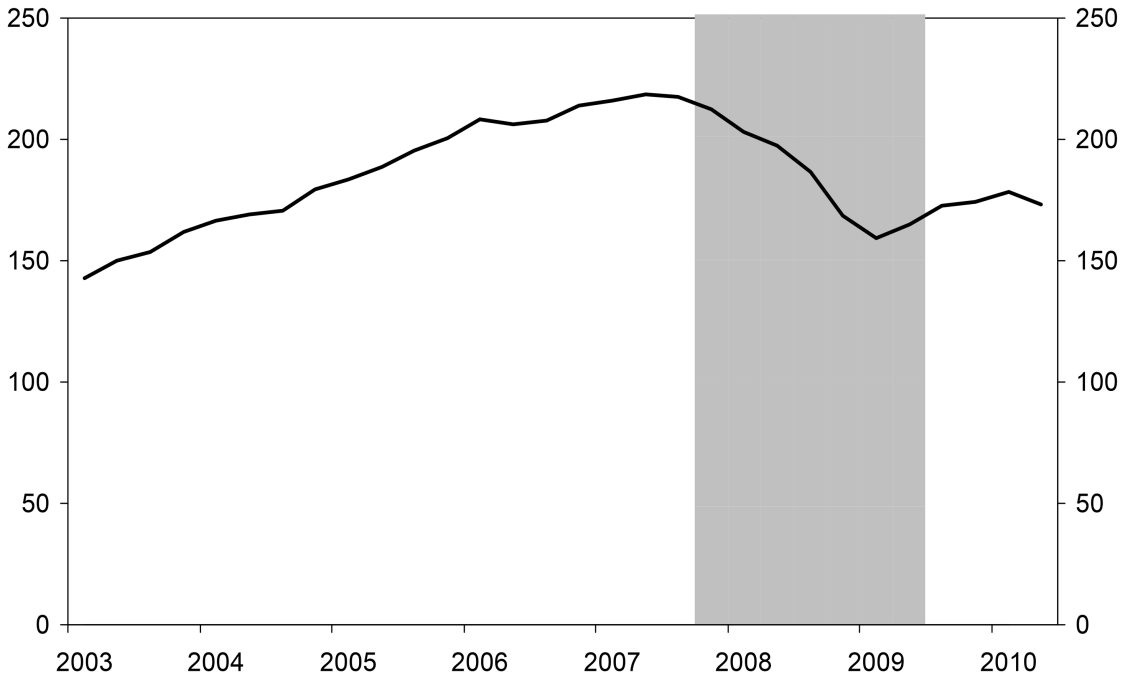

Fig. 9.10 Net worth (per capita)

Source: Flow of Funds Accounts, NSA, and current dollars. 


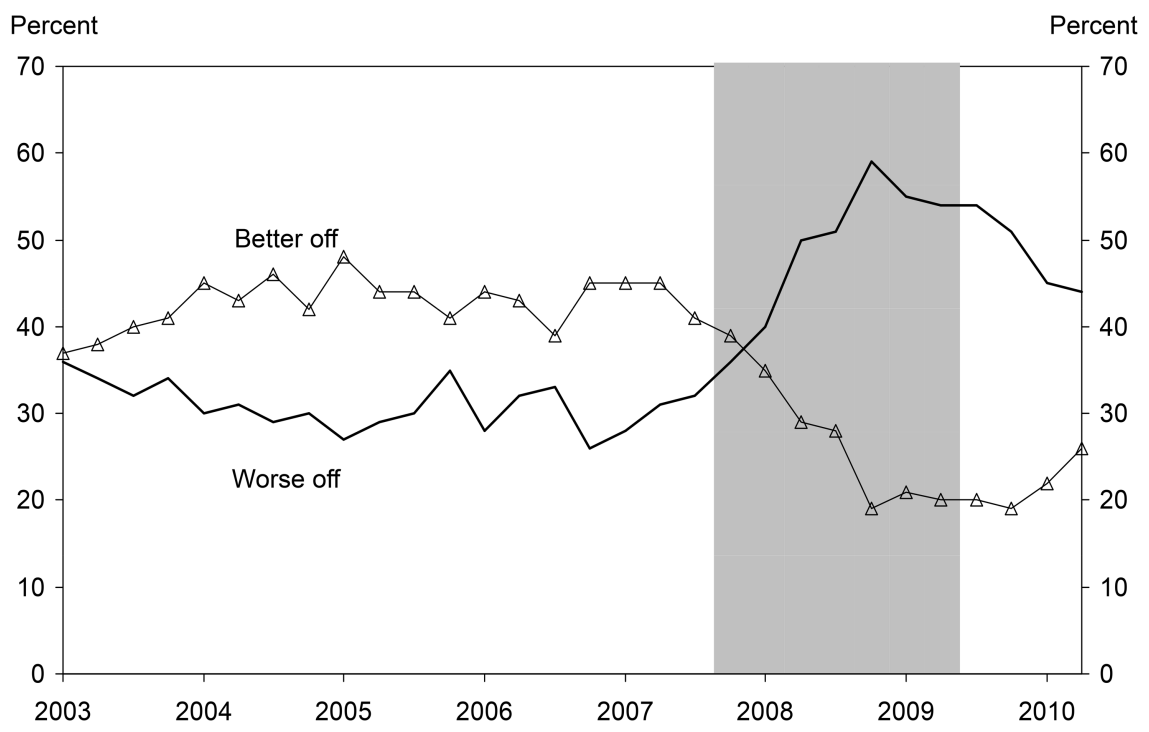

Fig. 9.11 Perceived decline in financial situation (percent worse off compared to year ago)

Source: Reuters/University of Michigan Survey of Consumers.

cially relative to a year ago, with older and lower-income individuals more likely to report to be worse off than younger and higher income individuals.

An alternative and arguably more objective measure of financial stress can be derived based on some of the RAND survey findings discussed earlier. In November 2008, about one-third of all individuals reported at least one of three indicators of financial distress: self or spouse unemployed, have negative equity in their home, or lost more than 30 percent of their retirement savings. While unemployment and negative home equity were more concentrated among younger individuals, large retirement savings losses were more common among those forty years of age or older, and especially among the forty to fifty-five age group. Comparing across income groups, we find that while unemployment was more frequently experienced by individuals in low-income families, negative equity and large retirement savings losses were instead much more common in higher-income households. The same is true when comparing those with and without college degrees. Finally, while individuals living in the bubble states were equally likely to report large retirement savings losses as those in other states, they were much more likely to be unemployed and underwater at the end of 2008.

During the November 2009-January 2010 interview period, large proportions of respondents in the NYFed survey continued to report deteriorating personal financial conditions, with 36 percent reporting being worse off and only 13 percent reporting being better off than a year earlier. As in the 


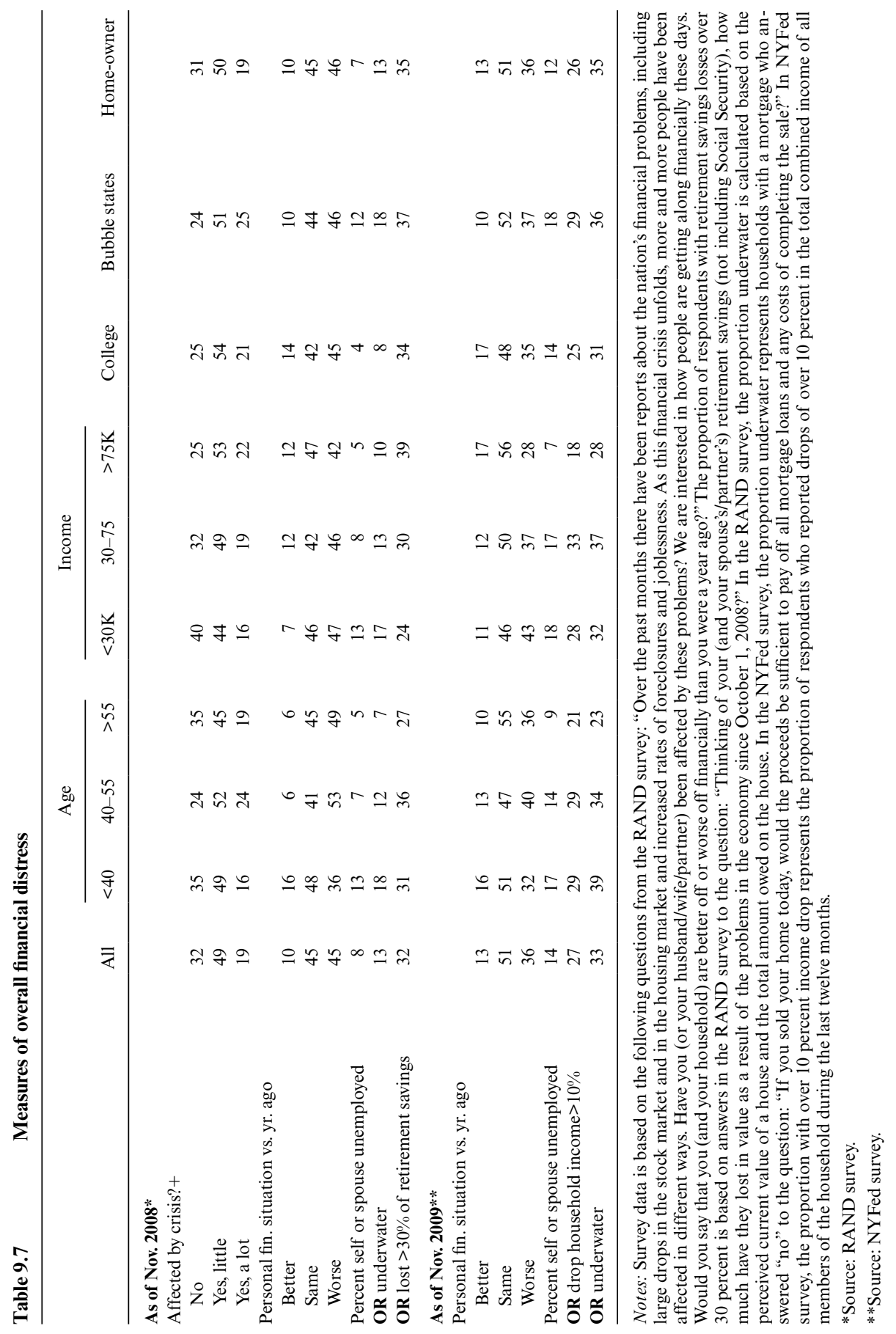


end-of-2008 RAND survey, a larger fraction of individuals in the forty to fifty-five age range reported worsening conditions. About a third of respondents reported to have experienced one of three types of financial distress: currently unemployed or have a spouse who lost his/her job during the past year, experienced a drop in household income over 10 percent compared to the previous year, or currently being underwater on their mortgage. The proportion reporting at least one of these types of distress is somewhat higher among those younger than forty (39 percent) and with incomes in the $\$ 30,000$ to $\$ 75,000$ range (37 percent), and lowest among individuals over age fifty-five (23 percent) and with incomes above $\$ 75,000$ (28 percent).

All in all, the survey evidence indicates that while different segments of the population were affected in distinct ways depending on whether they owned a home (and when they bought it and where it was located), whether they owned stocks, and whether they had secure jobs, the crisis' impact appears to have been widespread, affecting large shares of households across all age, income, and education groups.

\subsection{How Did Households Respond to the Changes in Economic Conditions?}

After investigating the nature and prevalence of deteriorating economic conditions during the 2007 recession, we focus next on how households responded to these changing conditions in their financial decision making. We first discuss changes in consumer spending behavior, followed by an analysis of changes in saving behavior. In examining how, at the individual household level, saving behavior may have changed, we consider the extent to which households changed their allocations to retirement accounts and how much they added or withdrew funds from other savings accounts. We also analyze in detail whether and how households reduced or increased their outstanding mortgage and nonmortgage debt.

\subsubsection{Consumer Spending}

After reaching a peak in the fourth quarter of 2007, ending a long period of steady growth, real personal consumption expenditures were down 3.1 percent by the second quarter of 2009 and remained 2.4 percent below the peak in the fourth quarter of 2009 (figure 9.12). Between the end of 2007 and the second quarter of 2009, real personal expenditures on goods fell by 7.2 percent (with durable goods expenditures falling 9.9 percent), expenditures on services fell by only 1.0 percent, and expenditures on food and beverages purchased for off-premises consumption fell by 3.1 percent. $^{16}$

16. Expenditures on goods, services, and food at the end of 2009 remained, respectively, 5.4 percent, 0.8 percent, and 1.6 percent below their levels attained at the end of 2007 (Bureau of Economic Analysis, NIPA). 


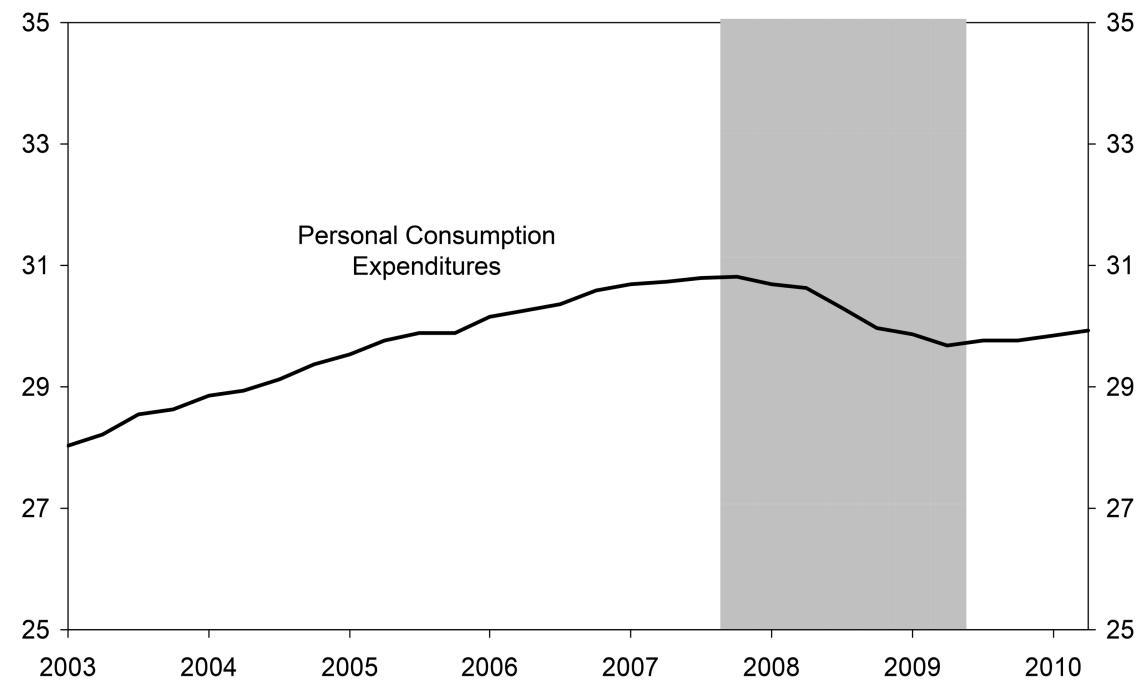

Fig. 9.12 Spending per capita

Source: BEA (NIPA).

Figure 9.13 provides additional information regarding the sharp drop in spending that occurred during the last quarter of 2008 and the first quarter of 2009. Daily discretionary consumer spending as measured by the Gallup daily poll dropped 40 percent during this period. ${ }^{17}$ While consumer spending rebounded somewhat after the first quarter of 2009, at the end of 2009 it remained about 28 percent below 3Q 2008 levels. Over the past two-year period, the average percentage change in daily discretionary spending has been very similar for lower- and middle-income individuals (defined by Gallup as incomes below \$90,000) and high-income individuals (incomes above $\$ 90,000)$.

Evidence from the RAND and NYFed surveys is consistent with these findings. As shown in table 9.8, as stock prices fell sharply, 75 percent of households reduced their monthly spending between October 1, 2008, and the interview date in November 2008, with a median cut reported of 20 percent or about $\$ 200$. Spending cuts across demographic groups were similar, except that among individuals fifty-five-years-of-age or older a somewhat smaller share reported reductions in spending, and on average reported smaller spending cuts. Percentage wise, cuts fell with household income,

17. Discretionary spending in the Gallup poll is defined as the money spent or charged during the previous day on all types of purchases, such as at a store, restaurant, gas station, online, or elsewhere, excluding purchases of a home, motor vehicle, or normal household bills. 


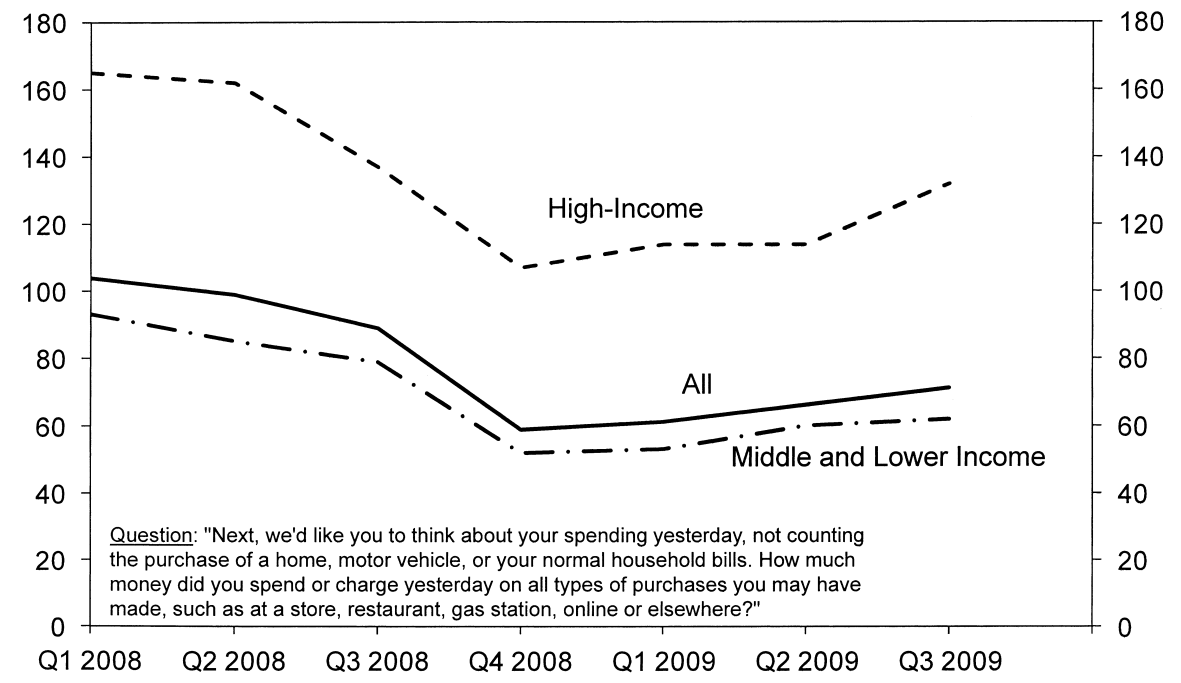

Fig. 9.13 Daily discretionary consumer spending

Source: Gallup poll.

Note: High income $=$ income over $\$ 90,000$.

with those with incomes below $\$ 30,000$ cutting spending by 25 percent, while those with incomes above $\$ 75,000$ cutting spending by 15 percent.

At the time of the NYFed survey (fielded between November 2009 and January 2010), a slightly higher proportion of individuals reported their current spending to be lower compared to a year ago (27 percent) than the proportion for whom it was higher ( 22 percent). On average, households reported spending to be 2.2 percent lower at the end of 2009 than it was a year earlier, with those age forty to fifty-five, with incomes under $\$ 30,000$, and living in a bubble state reporting larger percentage cuts, while older and higher-income individuals making smaller or no spending cuts (see table 9.8). The median change in spending was 0 percent, which is broadly consistent with the relatively flat trend in personal consumer expenditures that followed the large drop in spending at the end of 2008 shown earlier in figure 9.12 .

Not surprisingly, spending cuts are strongly related to measures of financial distress. As shown in table 9.9, the large majority of those unemployed at the end of 2009 reported cuts in spending during the year, with spending falling on average by more than 18 percent for this group. Similarly, those who reported household income losses of over 10 percent during 2009 and those who reported to be underwater on their mortgage reported spending approximately 10 percent and 6 percent less on average compared to a year 


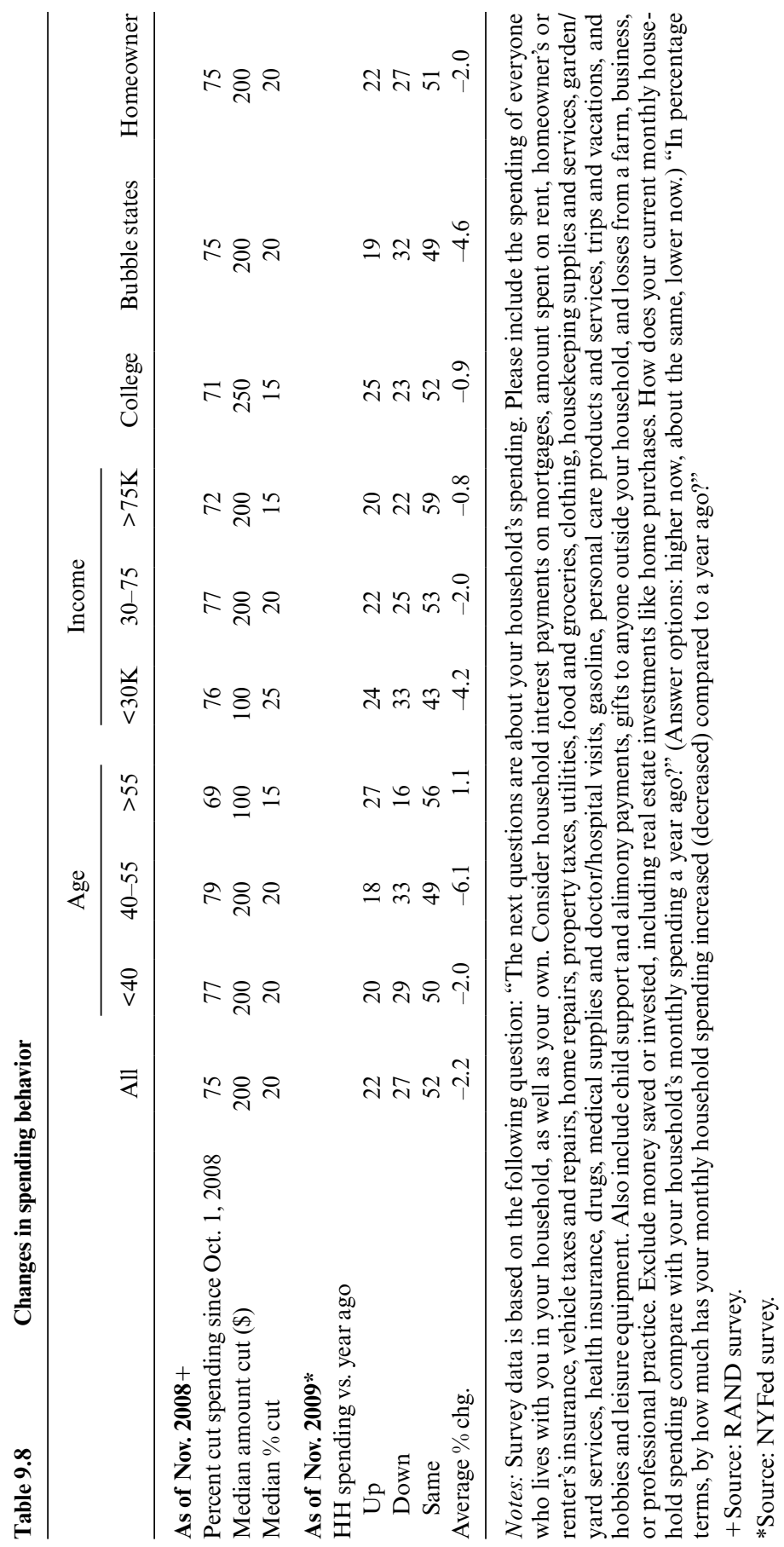


Spending behavior and wealth and income losses

\begin{tabular}{lcccc}
\hline & All & Unemployed & Lost $>10 \%$ income & Underwater \\
\hline As of Nov. 2009* & & & & \\
HH spending vs. year ago & & & & \\
$\quad$ Up & 22 & 5 & 21 & 18 \\
Down & 27 & 60 & 48 & 47 \\
$\quad$ Same & 52 & 35 & 31 & 35 \\
Average \% chg. & -2.2 & -18.2 & -9.6 & -5.9 \\
\hline
\end{tabular}

*Source: NYFed survey. See notes to table 9.8.

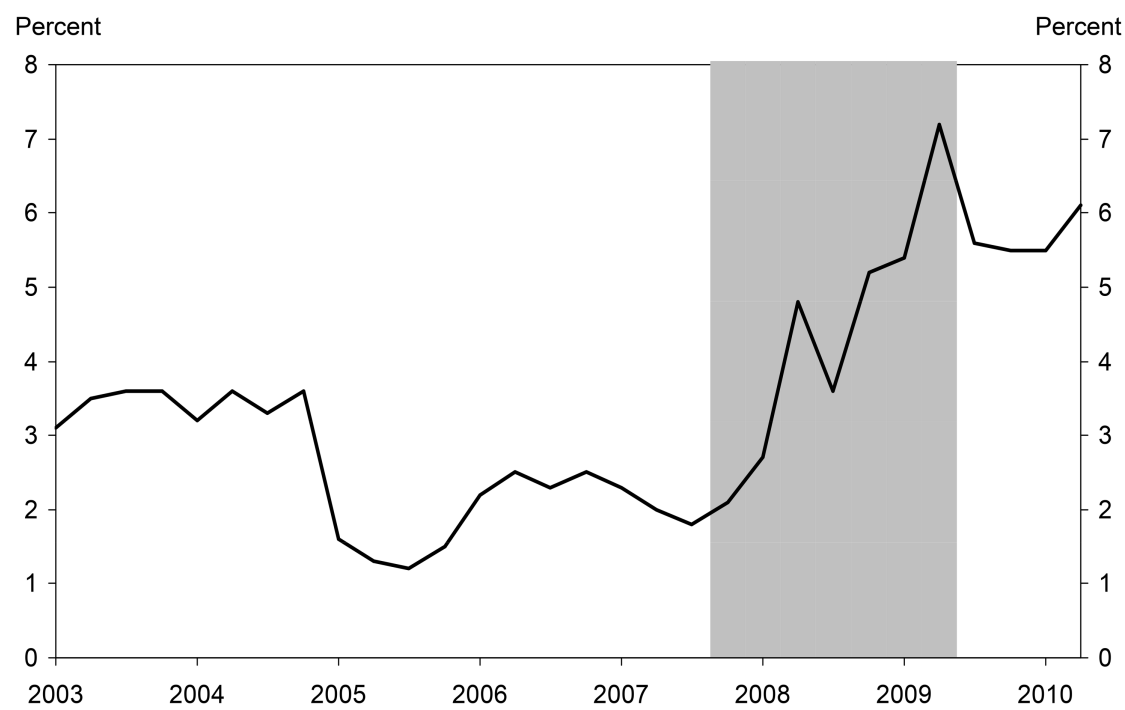

Fig. 9.14 Personal saving rate. Personal saving as percent of disposable personal income

Source: BEA (NIPA).

Note : Personal savings rate $=$ Personal savings/disposable personal income .

earlier, cuts much higher than the 2.2 percent average decline in spending during this period in our sample.

\subsubsection{Saving}

The relatively stable level of per capita disposable income shown earlier in figure 9.7 combined with what appears to be a persistent drop in personal consumption expenditures has resulted in a significant and widely reported increase in personal saving and in the personal saving rate. As shown in figure 9.14, the National Income and Products Accounts (NIPA) Personal Saving Rate as computed by the Bureau of Economic Analysis increased from historically low levels of around 1 percent in the first quarter of 2008 to 
recent levels over 6 percent. While the personal saving rate does not directly map into actual household saving, ${ }^{18}$ at the microeconomic level an increase in household saving could manifest itself as an increase in allocations to retirement and savings accounts. Alternatively, it could exhibit itself as an increase in allocations used to reduce or pay off debt; this could be mortgage debt or debt on other consumer loans such as auto, student, and credit card loans. In what follows we first present survey evidence on recent changes in allocations to retirement and other savings accounts. This is followed by an analysis of survey and administrative data on changes in consumer debt.

\section{Consumer Allocations to Retirement and Other Savings Accounts}

In the NYFed survey conducted during the November 2009-January 2010 period, we asked individuals whether they had made any changes to their retirement account contributions over the past year. As reported in table 9.10, while 11 percent of all individuals increased their contributions and 3 percent started contributing to a retirement account (including defined-contribution accounts and IRAs) for the first time, 12 percent decreased their contributions, 16 percent stopped contributing all together, and 11 percent prematurely withdrew funds from their accounts. Those who increased their allocations did so by a median amount of $\$ 100$ per month, while those who decreased their allocations did so by a median amount of $\$ 150$ per month. ${ }^{19}$

Not only did more individuals report reducing their contributions to retirement accounts than increasing their contributions, more individuals also report having withdrawn funds from other savings accounts (including checking, savings, and money market accounts) than having added funds to them. The proportions of individuals who reported that they on net withdrew funds during the past year from their checking, savings, and money market accounts exceeded the proportions of respondents who reported that on net they had added funds to each of these accounts. In contrast, approximately equal proportions reported that they on net had added funds to their stock market accounts as had withdrawn funds from stock market accounts. All together 25 percent of individuals said they had added more than they used up of their total other (nonretirement) savings during the past year, with a median net annual increase of $\$ 5,000$. However, 38 percent reported that they actually used up more than they added, with a median reduction of $\$ 3,500$. Therefore, our survey evidence provides little support

18. For example, the NIPA measure includes income and outlays of nonprofit organizations.

19. We also asked individuals for the overall percentage change in the total amount of money in their retirement and other savings accounts over the past year, after including all contributions and withdrawals during the year as well as changes in the value of funds already in their accounts. Overall respondents reported an average 3.2 percent decline in their total retirement account balances and an average 5.1 percent decline in balances of their other savings accounts. Given the slight increase in average stock and bond values during the period considered, this is consistent with an overall net withdrawal of funds from those accounts. 


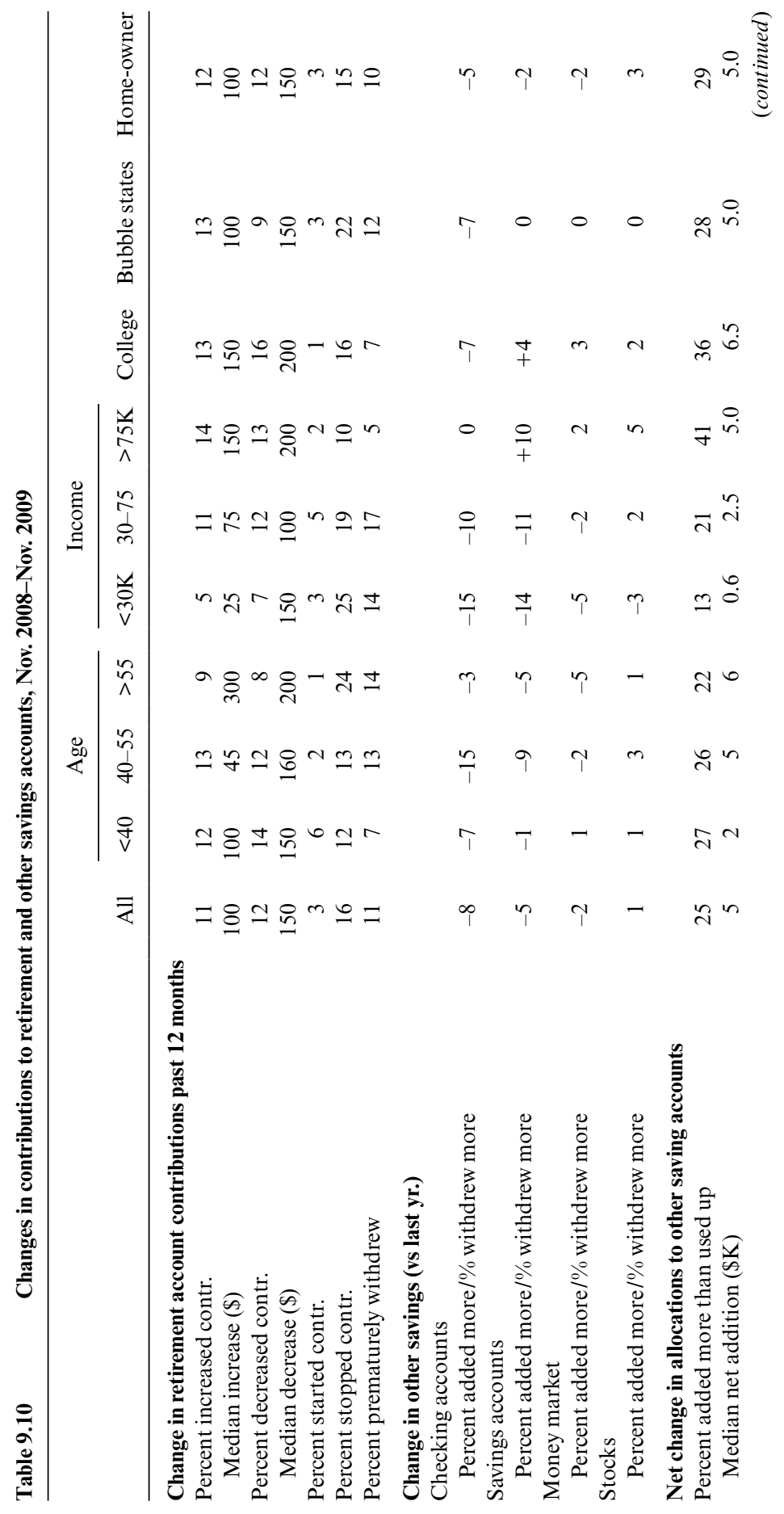




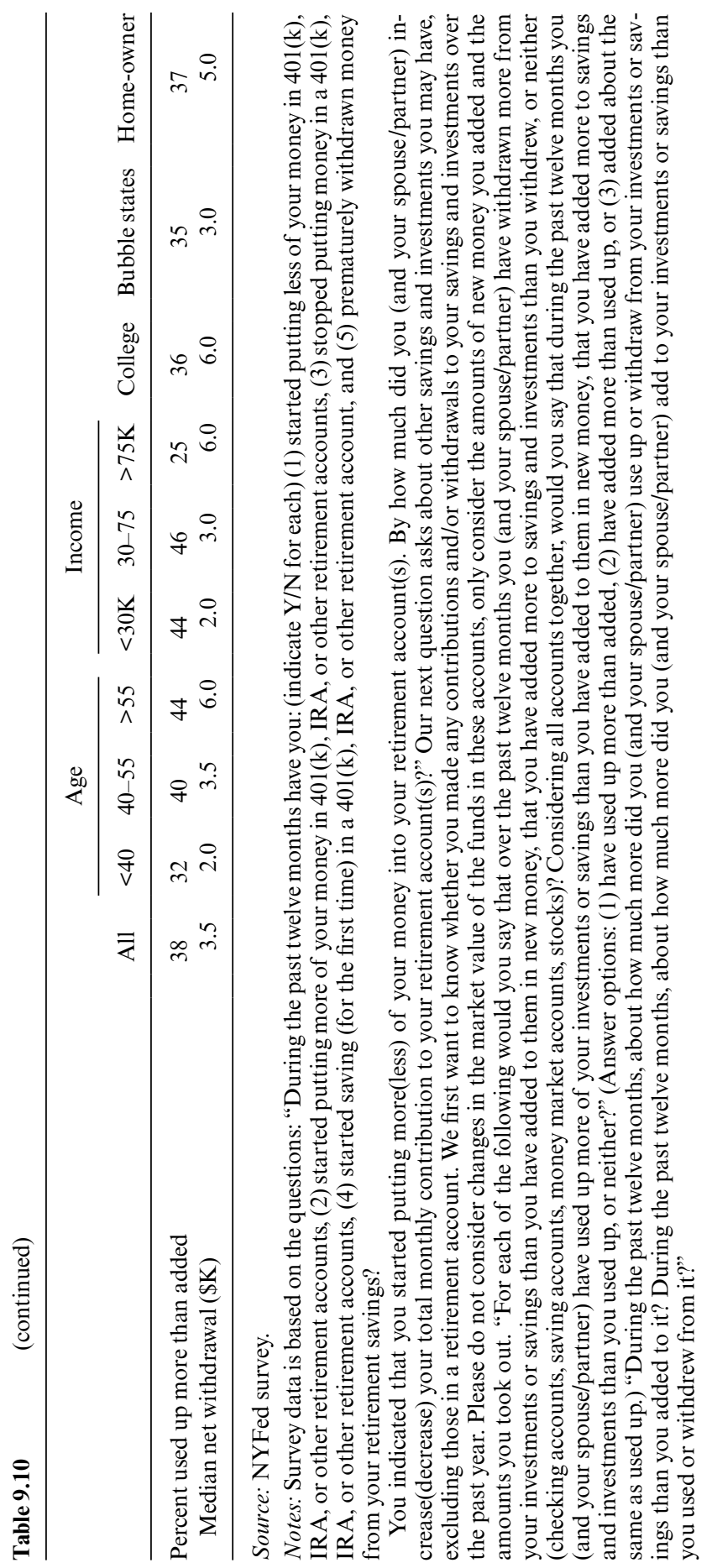


for the conjecture that households increased their saving by contributing more to their retirement and savings accounts.

Some of the observed changes in allocations to retirement and savings accounts undoubtedly reflect normal life cycle patterns in saving behavior, with retired individuals stopping to contribute and beginning to draw down their savings and younger individuals starting to save or to increase their saving as they advance in their careers. Some of the differences in reported behaviors across age groups in table 9.10 indeed seem to reflect such life cycle effects. However the changes reported in table 9.10, and especially the large proportions of respondents who stopped contributing or who prematurely withdrew funds during 2009 are much higher than one would expect to see in a more typical year.

The impact of the crisis is clearly reflected in the much higher proportion of lower-income households who stopped contributing or prematurely withdrew funds from their retirement accounts and the much lower proportion of households that increased contributions. These households were also much more likely to have used up more than they added to their other savings accounts. A higher proportion of higher-income households instead increased their contributions to their retirement account and reported net additions to their other savings account.

More insight into this issue is provided in table 9.11, which shows changes in allocations to retirement and other savings accounts for those unemployed at the end of 2009 and for those who experienced income losses over 10 percent during the past year. Between 90 and 100 percent of individuals belonging to these groups report decreasing or stopping their contributions

Allocations to savings accounts and wealth and income losses

\begin{tabular}{lcccc}
\hline $\begin{array}{l}\text { Change in retirement account contributions over } \\
\text { past 12 months }\end{array}$ & All & Unemployed & $\begin{array}{c}\text { Lost }>10 \% \\
\text { income }\end{array}$ & Underwater \\
\hline Percent increased contribution & 11 & 0 & 6 & 12 \\
$\quad$ Median increase (\$) & 100 & 150 & 80 & 5 \\
Percent decreased contribution & 12 & 28 & 27 & 50 \\
$\quad$ Median decrease (\$) & 150 & 150 & 150 & 2 \\
Percent started contributing & 3 & 0 & 2 & 9 \\
Percent stopped contributing & 16 & 41 & 29 & 9 \\
Percent prematurely withdrew & 11 & 16 & 19 & 16 \\
Net change in allocations to other saving accounts & & & & 3.0 \\
Percent added more than used up & 25 & 21 & 14 & 47 \\
$\quad$ Median net addition (\$K) & 5.0 & 8.0 & 3.0 & 3.6 \\
Percent used up more than added & 38 & 45 & 55 & \\
$\quad$ Median net withdrawal (\$K) & 3.5 & 2.0 & 3.5 & \\
\hline
\end{tabular}

Source: NYFed survey. See notes to table 9.10. 
or report prematurely withdrawing funds from their retirement account. A much higher share of these groups than in the rest of the sample also report having used up funds from their other savings accounts.

Among reasons provided, many respondents mentioned job, salary, and household income changes as playing a role in their decisions to increase or decrease their net contributions to their retirement and other savings accounts (table 9.12). Perhaps not surprisingly, among the reasons for increasing allocations, a desire to increase savings for retirement was the most

Table 9.12

Reasons provided for changing allocations to savings accounts

A. Reason for increase in contributions to retirement and other savings accountsproportion who list option as moderately or very important

\begin{tabular}{lcc}
\hline & Retirement accounts & Other savings accounts \\
\hline Job change & 27 & 29 \\
Salary change & 53 & 51 \\
Change in other income & 29 & 37 \\
To increase savings for retirement & 92 & 60 \\
Now is a good time to invest & 75 & 40 \\
To be able to leave a bequest & 23 & 19 \\
To make up for decline in value house & 19 & 15 \\
To make up for loss in stocks/investments & 33 & 23 \\
To build cushion for future job loss & n/a & 51 \\
To build cushion for future health expenses & n/a & 51 \\
\hline
\end{tabular}

B. Reason for decrease in contributions to retirement and other savings accountsproportion who list option as moderately or very important

\begin{tabular}{lcc}
\hline & Retirement accounts & Other savings accounts \\
\hline Job change & 31 & 26 \\
Salary change & 51 & 44 \\
Change in other income & 39 & 38 \\
Involuntary job loss & 31 & 22 \\
Voluntarily stopped working & 14 & 13 \\
To pay down/pay debt & 43 & 45 \\
To pay bills & 30 & 41 \\
To pay for general living expenses & 48 & 70 \\
\hline
\end{tabular}

Source: NYFed survey.

Notes: Panel A applies to those who responded that they reduced contributions or stopped contributing to their retirement account, while panel B applies to respondents who indicated that they had started putting money into or had increased contributions into a retirement account. The proportions in the table are based on responses to the following questions: "Please indicate how important each of the following was for the increase/decrease in your monthly contribution." (Answer options: very important, moderately important, not at all important, or not applicable.) "Please indicate how important each of the following was in your decision to withdraw some of your investments or savings (to add more to your investments or savings)." (Answer options: very important, moderately important, not at all important, or not applicable.) 
important factor, with "good time to invest" also often listed as motivation. Precautionary savings motives were listed as significant factors as well, while bequest motives and a desire to make up losses in home and stock values were less frequently mentioned. Among those who decreased net contributions to their retirement accounts or who used up funds from other savings accounts, a need or desire to pay for general living expenses, pay bills, and reduce debt were most frequently reported as motivations.

In our survey we also asked respondents to rate the importance to their household of a set of alternative reasons for savings in general. The findings, reported in table 9.13, show saving for retirement, precautionary savings motives, and saving to pay for a child or grandchild's education as the reasons most frequently listed as "very important." Saving for retirement is more frequently mentioned by those in the middle and older age groups and those with household incomes over $\$ 75,000$. Precautionary savings motives are generally more frequently mentioned by the forty to fifty-five age groups and those with household incomes under $\$ 30,000$. Saving to pay for the education of children or grandchildren or to buy a house or car is more frequently mentioned as an important reason for saving by younger individuals.

Finally, in addition to measuring changes in net contributions, it is interesting to analyze whether individuals made changes to how new funds or existing funds in their retirement and savings accounts were allocated. As shown in table 9.14, while approximately equal proportions increased and decreased the amount of new allocations used to buy stocks, a larger proportion of respondents rebalanced their stockholding by reducing their exposure to stocks in the first two months immediately following the stock market crash in October 2008, with about 3 percent pulling all funds out of the stock market. Similarly, 18 percent of respondents in the end-of-2009 survey indicated that they moved some of their retirement savings to less risky investments. This survey evidence suggests that a nonnegligible number of households appear to have shifted their allocations away from stocks, implying that not all consumers may have fully benefited from the recent rebound in the stock market.

\section{Recent Changes in Consumer Debt}

Before discussing our survey-based evidence on changes in consumer debt, we first describe recent findings based on the FRBNY Consumer Credit Panel, a unique and comprehensive administrative database of credit report records for a large random sample of US individuals and households. As shown in figure 9.15, after reaching a peak at the end of the third quarter of 2008 , overall household debt has fallen steadily, declining by about $\$ 567$ billion (4.5 percent) up to the end of December 2009.

In order to relate the observed change in total consumer debt to the NIPA measure of savings, we first distinguish between mortgage debt (on first mortgages, second mortgages, and home equity lines of credit [HELOCs]) 


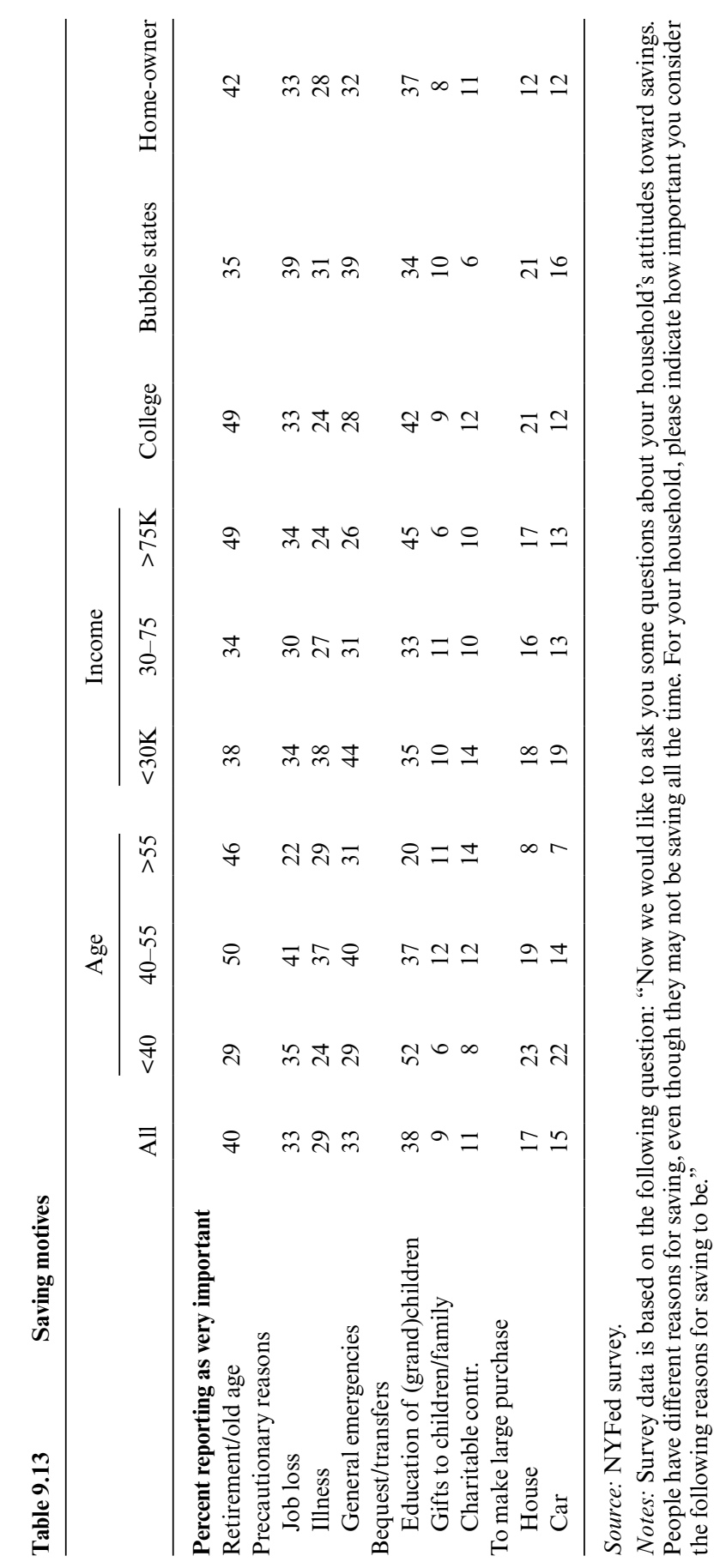




\section{Between Oct. 2008-May 2009*}

Allocations of new funds

Percent increased amounts to stocks

Percent decreased amounts to stocks

Allocation of balances

Percent increased amounts to stocks

Percent decreased amounts to stocks

Percent sold all stocks in retirement accounts

Between end 2008-end 2009+

Percent moved retirement savings into less risky investments

Notes: Survey data is based on the following question: "During the past twelve months have you ... moved your retirement savings into less risky investments? (Y/N)."

* Hurd and Rohwedder (2010).

+ NYFed survey.

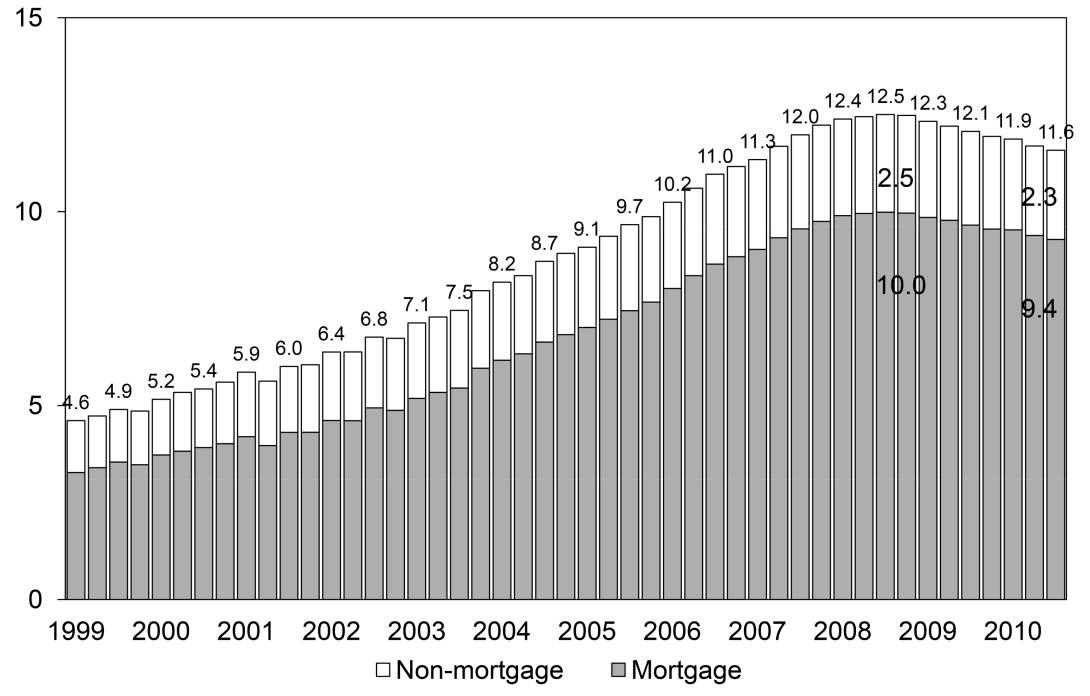

Fig. 9.15 Total debt balance and its composition

Source: FRBNY Consumer Credit Panel.

and nonmortgage debt (on credit card loans, auto loans, student loans, and other personal loans). Second, we exclude from the observed quarterto-quarter changes in overall mortgage debt all changes in debt associated with home transactions. Third, in computing changes in mortgage and nonmortgage debt, we exclude amounts charged-off by banks. The resulting 
Billions of Dollars

Billions of Dollars

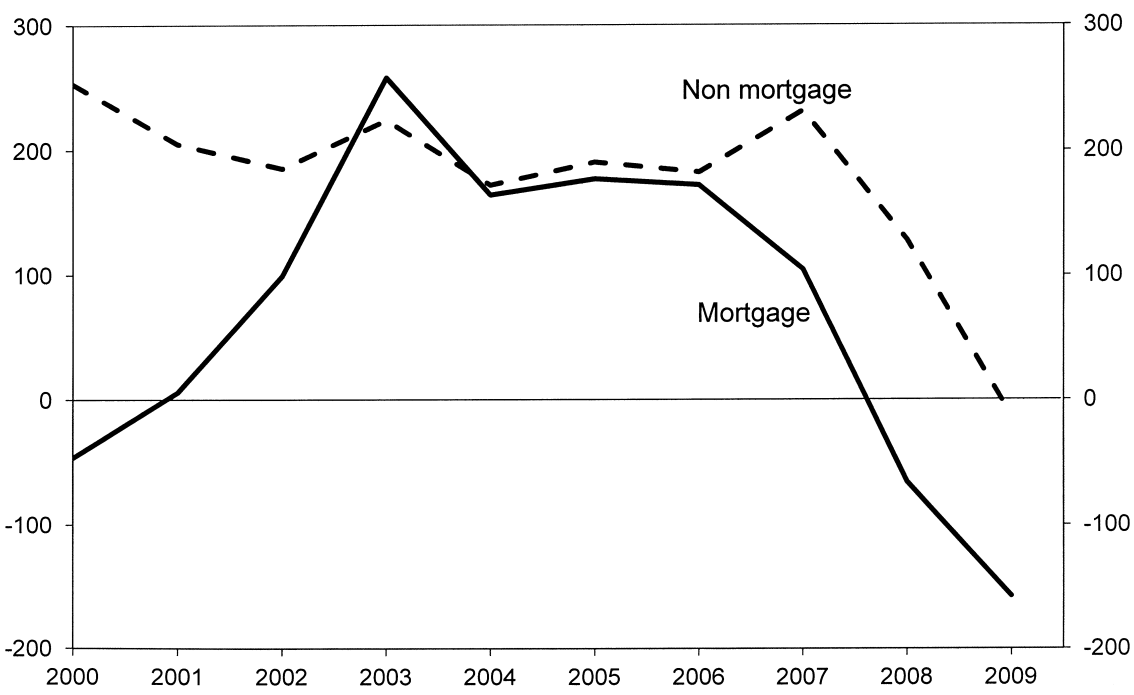

Fig. 9.16 Changes in household debt available for spending (annual)

Source: FRBNY Consumer Credit Panel.

measure describes how much individuals on average are paying down or adding to their debts. ${ }^{20}$

The trends in net changes in mortgage and nonmortgage debt, shown in figure 9.16, reveal that until 2008 net pay-down on mortgage debt was actually negative: the increases in debt associated with cash-out refinances, second mortgages, and HELOCs exceeded the total mortgage payments consumers were making to reduce mortgage principals. Since then, consumers have accelerated paying down mortgage debt and, in 2009, mortgage debt was reduced by 140 billion dollars. Similarly, in 2009 consumers on average started paying down their outstanding nonmortgage debt, even though by a much smaller amount. Differentiating by loan type, we find that while consumers were paying down auto loan debt, student loan debt has been growing rapidly.

The evidence from the NYFed survey shown in table 9.15 is broadly consistent with recent trends in the FRBNY Consumer Credit Panel. A considerably larger proportion of respondents report decreasing rather than increasing their mortgage debt, with declines in mortgage debt reported most frequently among the forty to fifty-five age and high-income groups. While most individuals who reduced mortgage debt reported doing so by making their scheduled mortgage payments, about 17 percent mentioned doing so in part by prepaying principal and 11 percent did so in part through

20. For further explanation and details of this analysis see Brown et al. (2010). 


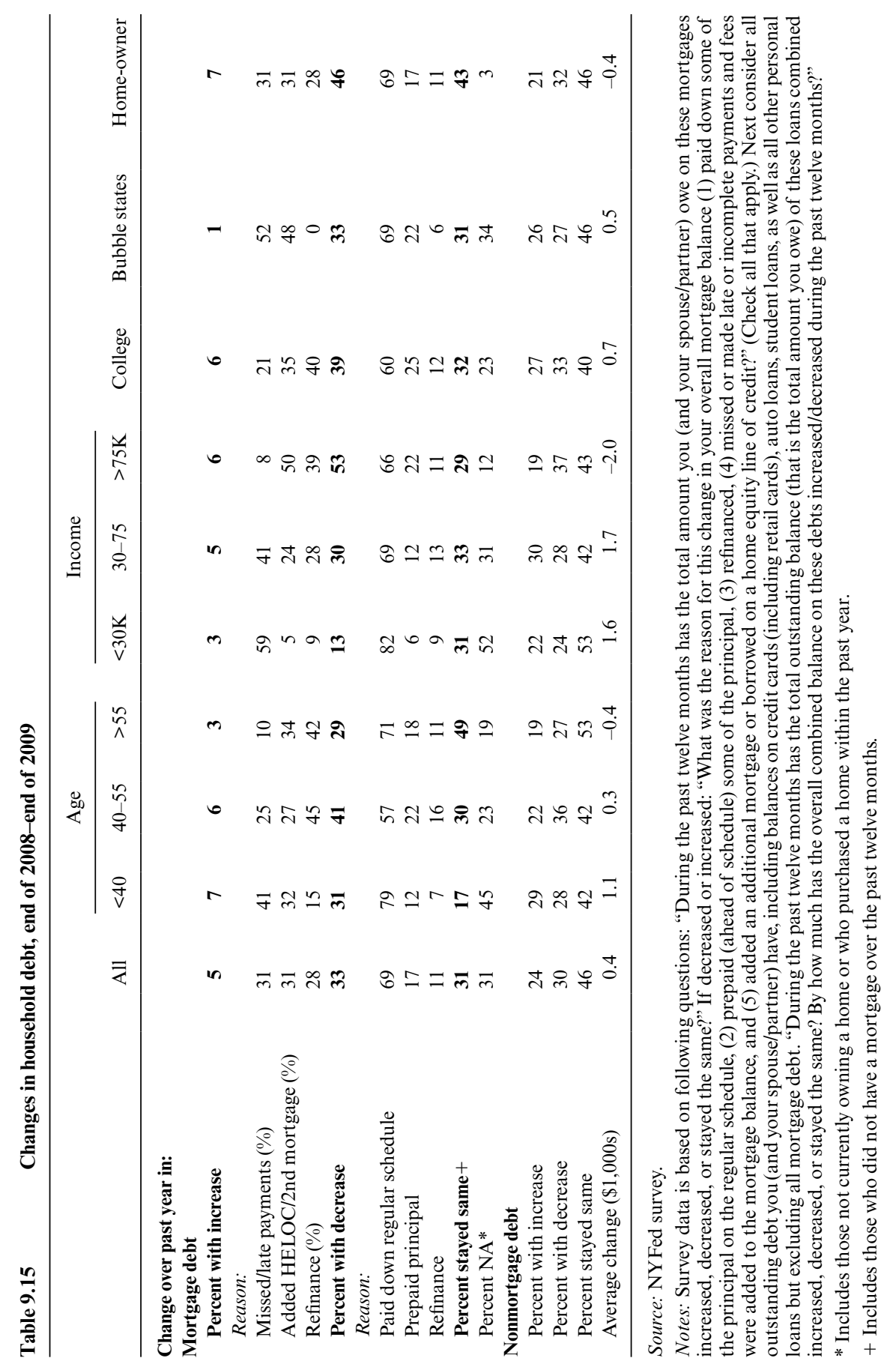


Table 9.16

Changes in household debt for affected subgroups

\begin{tabular}{|c|c|c|c|c|}
\hline Change over past year in: & All & Unemployed & Lost $>10 \%$ income & Under-water \\
\hline \multicolumn{5}{|l|}{ Mortgage debt } \\
\hline Percent with increase & 5 & 12 & 10 & 11 \\
\hline Percent with decrease & 33 & 19 & 31 & 45 \\
\hline Percent stayed same+ & 31 & 19 & 33 & 39 \\
\hline Percent $\mathrm{n} / \mathrm{a}^{*}$ & 31 & 50 & 26 & 5 \\
\hline \multicolumn{5}{|l|}{ Nonmortgage debt } \\
\hline Percent with increase & 24 & 30 & 31 & 36 \\
\hline Percent with decrease & 30 & 39 & 31 & 34 \\
\hline Percent stayed same & 46 & 31 & 38 & 30 \\
\hline Average change $(\$ 1,000 \mathrm{~s})$ & 0.5 & 2.3 & 0.5 & 2.6 \\
\hline
\end{tabular}

Source: NYFed survey. See notes to table 9.15.

* Includes those not currently owning a home or purchased a home within the past year.

+ Includes those who did not have a mortgage over the past twelve months.

a refinance. Prepaying and refinancing were more frequently reported by higher-income individuals and college graduates. These findings suggest that at least a substantial share of households who reduced their outstanding mortgage debt did so voluntarily.

Interestingly, our survey results provide little evidence that households also reduced nonmortgage debt during the past year. While overall a slightly larger share of households reduced than increased such debt, on average, debt increased by about $\$ 400$ during the past year. Declines in nonmortgage debt were more likely to be reported by older individuals and those with household incomes above $\$ 75,000$. The latter group of respondents actually reported reducing their nonmortgage debt on average by $\$ 2,000$ during the past year. Overall, this survey evidence is consistent with the findings of households paying down mortgage debt presented earlier in figure 9.16, but with little if any reductions in outstanding nonmortgage debt.

Not surprisingly, individuals who were unemployed at the end of 2009 were less likely to report reductions in their mortgage debt and more likely to report increases (table 9.16). They were also more likely to report increases in their nonmortgage debt, but a greater share of such individuals also reported decreases in nonmortgage debt. ${ }^{21}$ Overall, unemployed individuals reported adding to their nonmortgage debt by $\$ 2,300$, on average. Similarly, respondents from households that experienced an income drop of more than 10 percent during the year also were more likely to report increases in their mortgage and nonmortgage debt.

21. Unfortunately, we cannot evaluate with our data the extent to which the observed declines in mortgage and nonmortgage debt of individuals were due to lenders tightening standards and reducing limits on revolving credit lines during this period. 


\section{Responses in Spending and Savings to Hypothetical Income Shocks}

To get an alternative view of household preferences and intentions for saving and spending, we asked respondents about their intended responses to a positive shock in their year-ahead income, as well as a negative income shock, to account for a possible asymmetry in intended response behavior. Responses to both questions are shown in table 9.17. Overall, 99 percent of respondents say they would at least use part of the extra income to save, invest, or pay down debt, with 61 percent of all respondents saying that they would in fact use all the extra income for saving and/or for paying down debt. Only 1 percent of individuals say that they will spend or donate it all, with another 39 percent saying they would spend only some of the extra income. Aggregated across all individuals, on average 41 percent of the extra income would be used for saving/investing, 44 percent for debt payoff, and only 15 percent for spending. Comparing across demographic groups, we find surprisingly little differences in the expected shares of income to be used for consumption.

Faced with an unexpected income drop, respondents instead expect to respond mainly by reducing their spending. Overall, 53 percent of respondents expect to reduce spending by the full amount of the shortfall. Only 13 percent expect to take on some more debt to cover the shortfall, while 41 percent expect to use some of their savings to cover the lost income. On average, individuals expect to cover about 74 percent of the income loss by cutting spending, 20 percent by using some of their savings, and 6 percent by borrowing.

Care must be taken in interpreting stated intentions as actual future behavioral responses to realized income surprises. However, the findings appear to suggest that consumers will be unlikely to increase spending by much if their incomes were to increase by more than expected, while on the other hand, they seem likely to cut spending quite drastically in response to an unexpected future income shortfall.

\subsection{Households' Expectations of Future Conditions and Behaviors}

In this section we analyze what households are expecting for the future. In the NYFed survey we asked a number of questions eliciting individuals' expectations regarding a variety of outcomes and decisions, including their household's income, spending, saving behavior, and retirement plans.

We first discuss individuals' expectations reported at the end of 2009 about overall economic conditions during the following twelve months. As shown in table 9.18, more respondents expect to see increases than decreases in the unemployment, loan interest, and mortgage rate. However, a slightly higher share expect an increase rather than a decrease in the average house price at the national level, but on average expecting an increase of only 


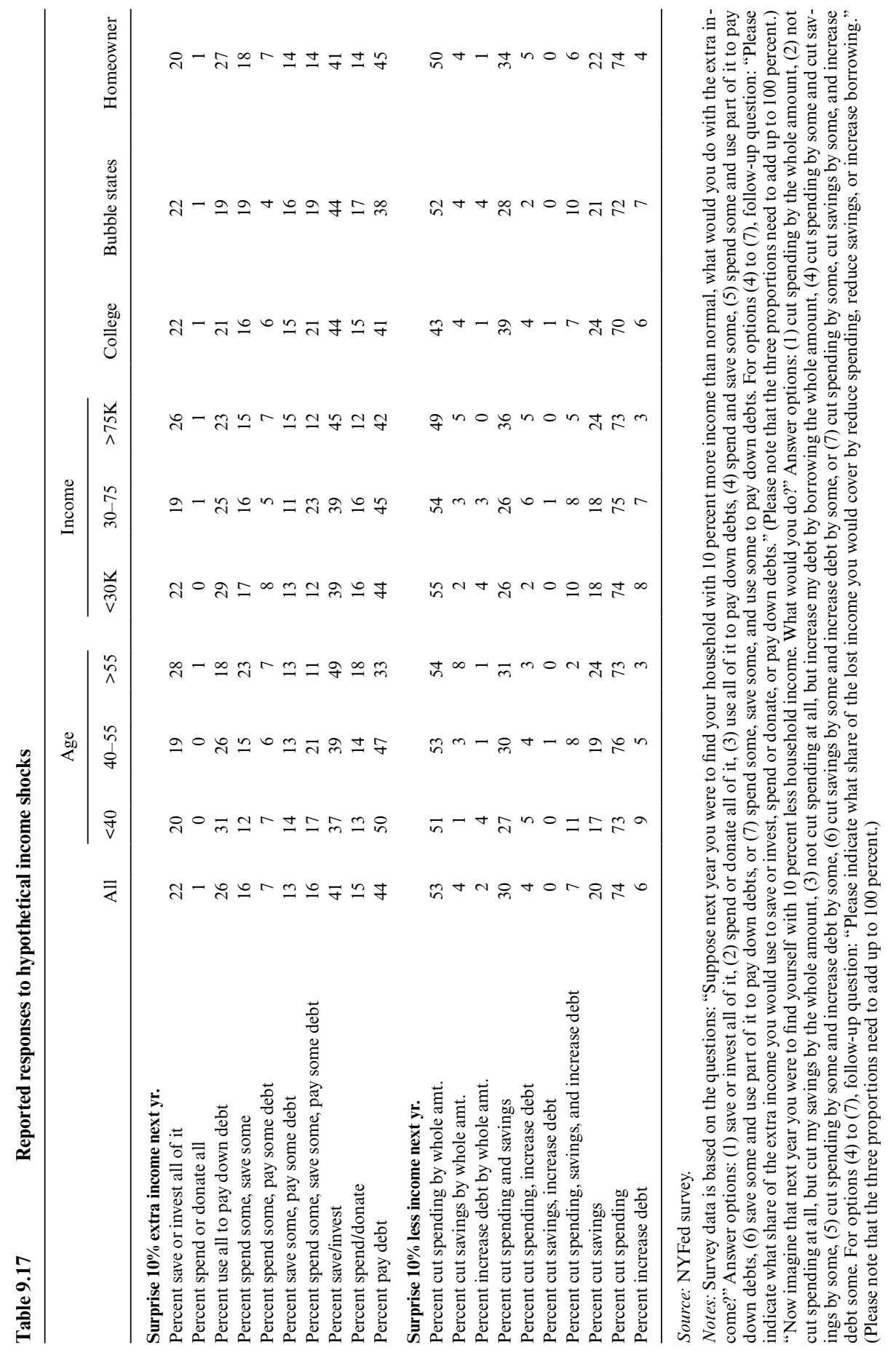




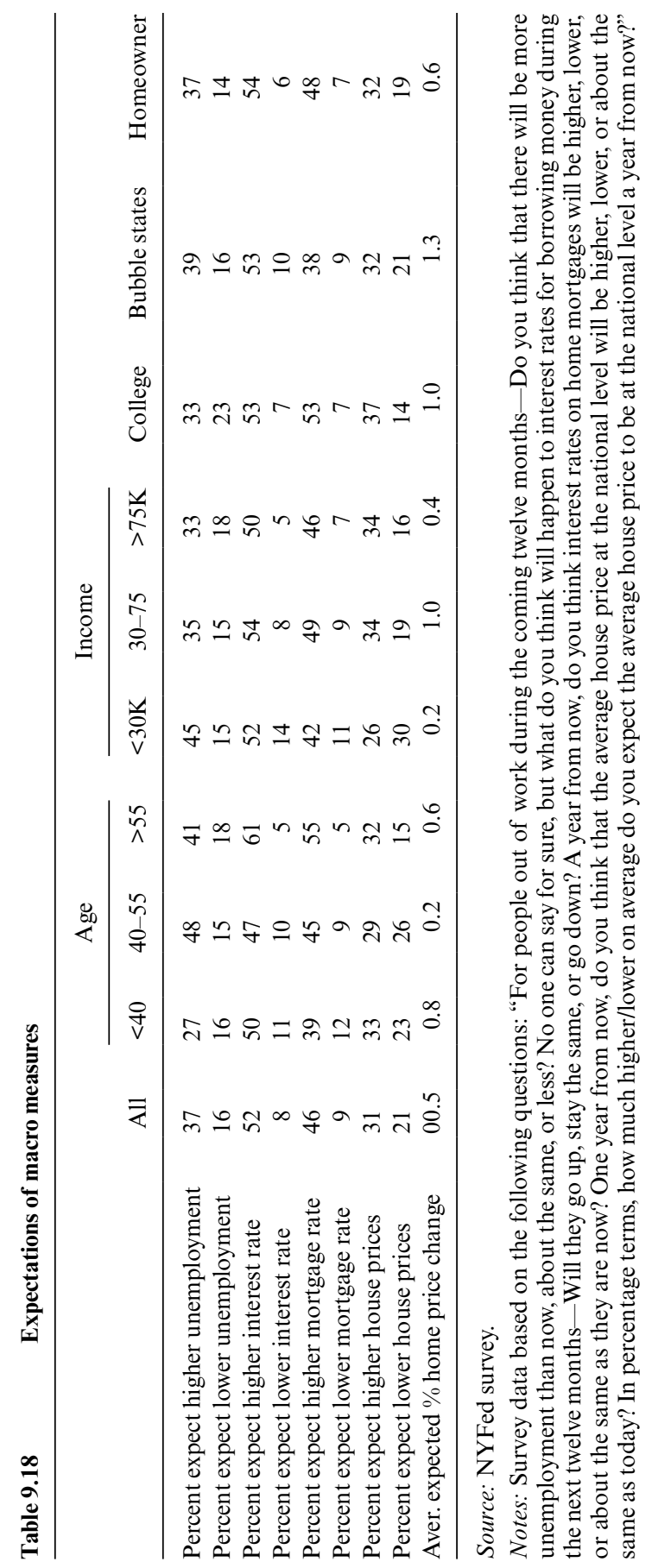




\begin{tabular}{lcccc}
\hline & All & Unemployed & $\begin{array}{c}\text { Lost }>10 \% \\
\text { income }\end{array}$ & Underwater \\
\hline Percent expect higher unemployment & 37 & 30 & 30 & 44 \\
Percent expect lower unemployment & 16 & 26 & 18 & 8 \\
Percent expect higher interest rate & 52 & 34 & 49 & 59 \\
Percent expect lower interest rate & 8 & 5 & 10 & 0 \\
Percent expect higher mortgage rate & 46 & 28 & 51 & 54 \\
Percent expect lower mortgage rate & 9 & 15 & 8 & 5 \\
Percent expect higher house prices & 31 & 19 & 38 & 42 \\
Percent expect lower house prices & 21 & 20 & 17 & 24 \\
Aver. expected \% home price change & 0.5 & -0.7 & 1.6 & 1.9 \\
\hline
\end{tabular}

Source: NYFed survey. See notes to table 9.18.

0.5 percent during 2010. Perhaps not surprisingly, expectations about overall economic conditions vary with experiences of financial distress. As shown in table 9.19, those who are underwater are more likely to expect higher unemployment, interest, and mortgage rates. Expectations for those who are unemployed or those who reported household income losses of over 10 percent during 2009 do not depict the same pessimistic picture. In fact, expectations for this group tend to be more optimistic relative to our sample. It is also notable that those who report to be underwater are more likely to expect home prices to rise in the future, and to expect a higher mean increase in home prices relative to the entire sample.

Tables 9.20 and 9.21 report expectations about a number of personal outcomes and decisions. Considering first year-ahead expectations of household incomes, while there exists considerable heterogeneity in expectations across individuals, overall respondents are reasonably optimistic, expecting an average increase of 4.1 percent in their household income over the next twelve months. Expected increases are higher on average among youngerand lower-income respondents, while older- and higher-income respondents instead on average expect a small decline in their household incomes. ${ }^{22}$ Expected increases are highest on average for financially distressed respondents, that is, those who report to be unemployed at the end of 2009 and those who report to have lost over 10 percent of household income in 2009 (table 9.21). This is consistent with respondents anticipating finding a job or experiencing an income rebound in the next twelve months. A similar pattern is found for wage expectations (asked of those who were employed at the

22. Clearly some of these responses reflect expectations of nonlabor income, life cycle behavior (expected retirement) and rebounds in income by the unemployed expecting to find work. 


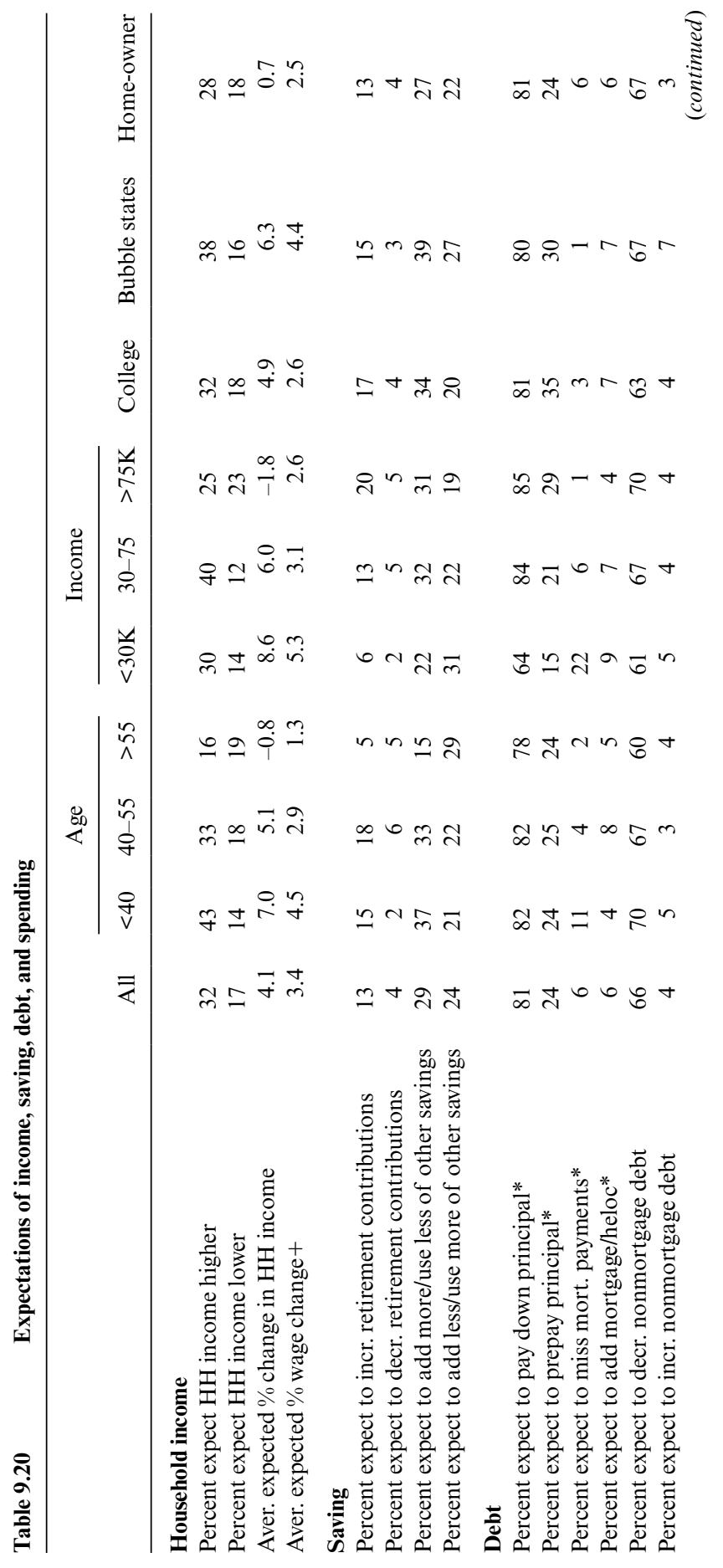




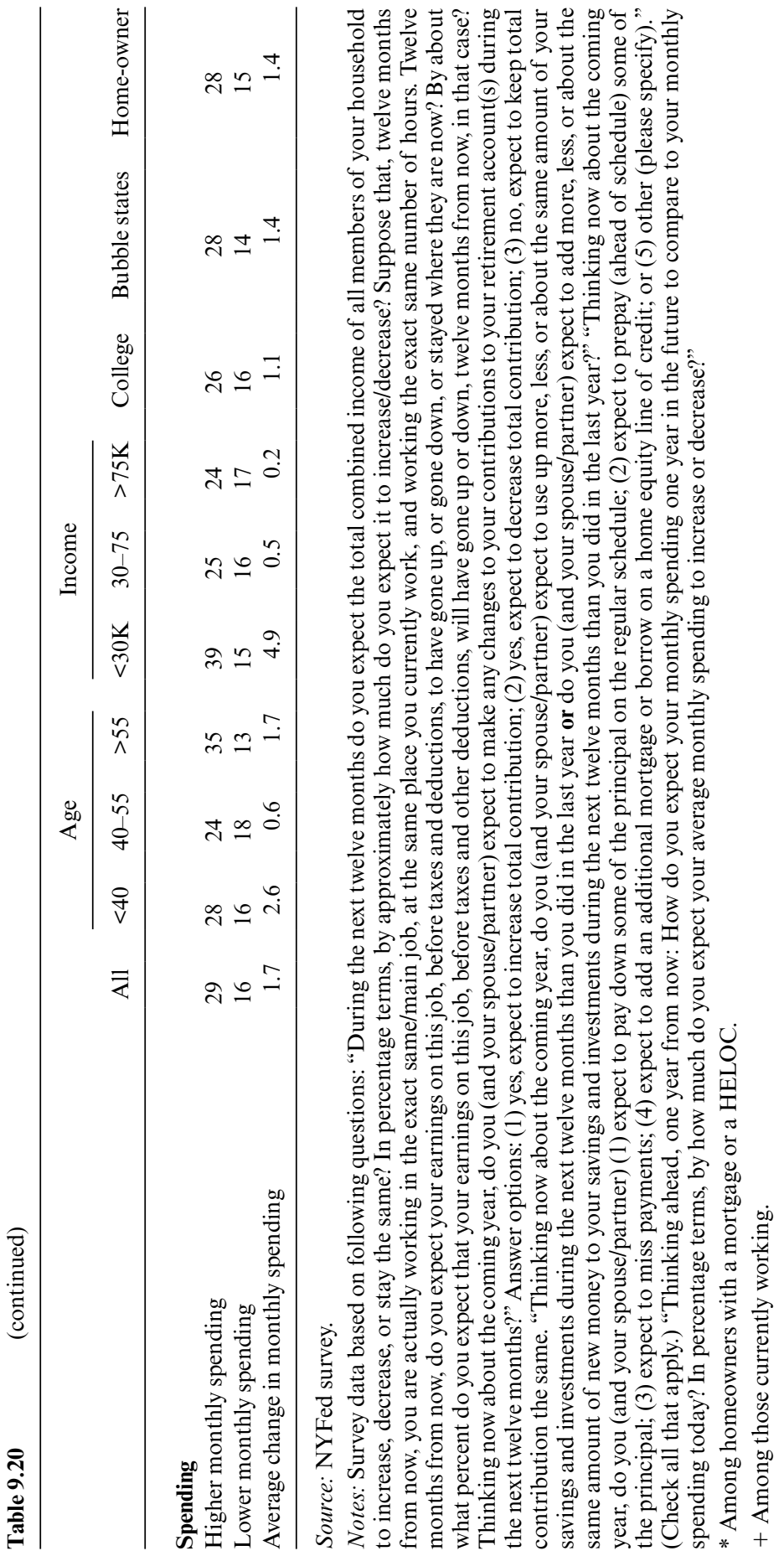




\begin{tabular}{lcccc}
\hline & All & Unemployed & $\begin{array}{c}\text { Lost }>10 \% \\
\text { income }\end{array}$ & Underwater \\
\hline Household income & & & & \\
Percent expect HH income higher & 32 & 41 & 46 & 27 \\
Percent expect HH income lower & 17 & 26 & 21 & 16 \\
Aver. expected \% change in HH income & 4.1 & 11.1 & 10.5 & 1.7 \\
Aver. expected \% wage change+ & 3.4 & NA & 4.5 & 1.9 \\
Saving & & & & \\
Percent expect to incr. retirement contributions & 13 & 11 & 16 & 8 \\
Percent expect to decr. retirement contributions & 4 & 12 & 8 & 4 \\
Percent expect to add more/use less of other savings & 29 & 35 & 30 & 32 \\
Percent expect to add less/use more of other savings & 24 & 30 & 31 & 30 \\
Debt & & & & \\
Percent expect to pay down principal* & 81 & 65 & 81 & 71 \\
Percent expect to prepay principal* & 24 & 15 & 24 & 15 \\
Percent expect to miss mort. payments* & 6 & 30 & 11 & 13 \\
Percent expect to add mortgage/heloc* & 6 & 7 & 5 & 8 \\
Percent expect to decr. nonmortgage debt & 66 & 51 & 69 & 76 \\
Percent expect to incr. nonmortgage debt & 4 & 7 & 2 & 10 \\
Spending & & & & \\
Higher monthly spending & 29 & 30 & 25 & 30 \\
Lower monthly spending & 16 & 24 & 28 & 16 \\
Average change in monthly spending & 1.7 & 1.9 & -1.5 & 2.3 \\
\hline
\end{tabular}

Source: NYFed survey. See notes to table 9.20.

time of the survey at the end of 2009), with workers expecting an average 3.4 percent increase in their wages.

When asked whether they expect to make any changes to their retirement contributions over the next year, 13 percent report that they expect to increase their contributions, 4 percent expect to decrease contributions, and the remainder expect to keep them unchanged. Older individuals, those with low incomes, and those currently underwater are less likely to expect to increase their retirement account allocations. About 29 percent expect to add more or to use up less of their other savings accounts during the next year, while 24 percent instead expect to add less or use up more of their other savings. Overall, older and lower-income households plan to add less or use more of their other savings than their younger and more affluent counterparts.

While over 80 percent of homeowners with a mortgage expect to pay down some of the principal on their mortgage loans, some 24 percent expect to prepay some of the principal. Low-income individuals and those unemployed at the end of 2009 are least likely to expect to pay down some of the principal (64 percent) and least likely to expect to prepay some of the 
principal (15 percent). On the other hand, 6 percent of homeowners with mortgages expect to miss payments during the next year, with the rate being as much as 22 percent for those with incomes under $\$ 30,000$ and 30 percent for those unemployed. Interestingly, the share of households expecting to miss a mortgage payment during the next year is actually smaller (1 percent) in the bubble states than in the nation as a whole. Finally, another 6 percent of homeowners with mortgages are expecting to add an additional mortgage or a home equity line of credit.

Considering nonmortgage debt, we find that 66 percent of respondents expect to decrease their combined debt on credit cards, auto loans, and student loans and only 4 percent expect to increase it. Plans to reduce such debt are slightly more prevalent among younger individuals and higherincome individuals, and are the highest among individuals who report to be underwater on their mortgage.

A greater share of households expects to increase their monthly spending over the next twelve months than to decrease it. On average, household spending is expected to increase by 1.7 percent. Given an average expected increase in pretax household income of 4.1 percent, and assuming a similar increase in disposable income, this implies an average expected increase of 2.4 percent in saving or debt reduction. Closely tracking their expectations of household income increases, younger individuals, those with incomes under $\$ 30,000$, and those who are underwater expect the greatest increases in spending over the next twelve months.

We also elicited expectations about future retirement, bequests, and personal year-ahead overall financial situation. As shown in tables 9.22 and 9.23, 24 percent reported that they had postponed retirement, while 5 percent now plan to retire earlier. Plans to postpone retirement were most prevalent among workers over age fifty-five and workers with higher household incomes. Perhaps not surprisingly, given the loss of wealth experienced during the recession, more respondents report that the chance that they will leave an inheritance has fallen instead of increased during the past year, with declined chances more likely to be reported by those who are financially distressed.

Asked whether over the next twelve months they expect that it will generally become easier, harder, or equally difficult to obtain credit or loans compared to the past twelve months, about twice as many respondents expect credit conditions to worsen: 39 percent expect credit to become more difficult to obtain (with the rate being as high as 59 percent for those underwater), while 20 percent expect it to become easier.

Finally, significantly more respondents expect to be financially better off than worse off twelve months from now. Comparing across age and income groups, we find that younger individuals are far more optimistic than older individuals, but find little differences across income groups. Individuals who are most financially distressed report the most optimistic expectations. 


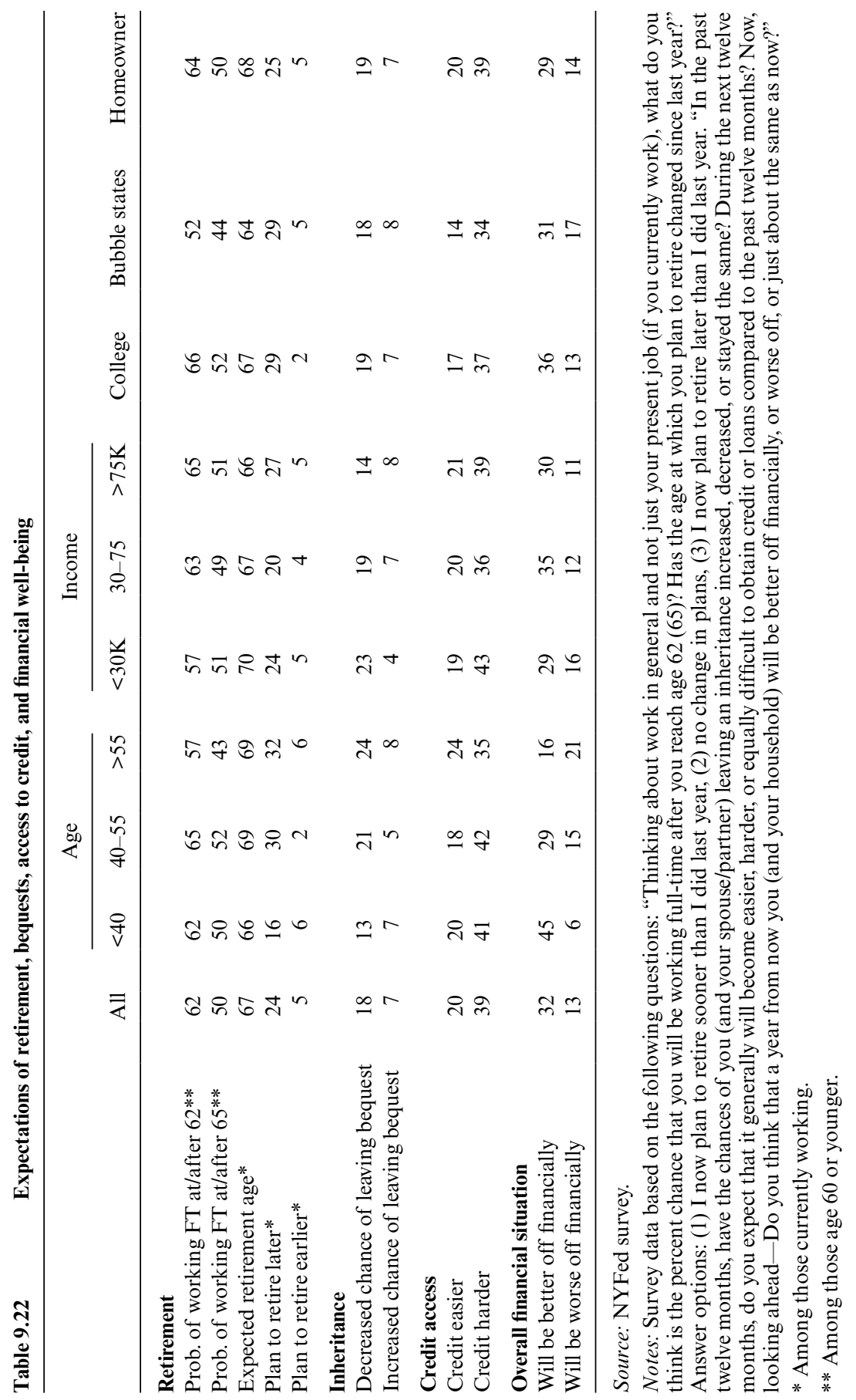


Table 9.23

Expectations of retirement, bequests, access to credit, and financial wellbeing for affected subgroups

\begin{tabular}{lcccc}
\hline & All & Unemployed & $\begin{array}{c}\text { Lost }>10 \% \\
\text { income }\end{array}$ & Underwater \\
\hline Retirement & & & & \\
Prob. working FT at/after 62** & 62 & 64 & 69 & 64 \\
Prob. working FT at/after 65** & 50 & 55 & 54 & 57 \\
Expected retirement age* & 67 & $\mathrm{n} / \mathrm{a}$ & 69 & 69 \\
Plan to retire later* & 24 & $\mathrm{n} / \mathrm{a}$ & 25 & 1 \\
Plan to retire earlier* & 5 & $\mathrm{n} / \mathrm{a}$ & 11 & 27 \\
Inheritance & & 32 & 35 & 31 \\
Decreased chance of leaving bequest & 18 & 20 & 6 & 3 \\
Increased chance of leaving bequest & 7 & & & \\
Credit access & & 20 & 18 & 12 \\
Credit easier & 20 & 33 & 41 & 59 \\
Credit harder & 39 & & & 34 \\
Overall financial situation & & 47 & 43 & 13 \\
Will be better off financially & 32 & 15 & 13 & \\
Will be worse off financially & 13 & &
\end{tabular}

Source: NYFed survey. See notes to table 9.22.

\subsection{Conclusion}

In this chapter we first documented the extent to which households were affected by the declines in the housing, stock, and labor markets as well as the heterogeneity in the impact of these declines across age, income, education groups, and geographic areas. Next, we analyzed the nature of behavioral responses to the shocks in income and wealth, including changes in spending, contributions to retirement and savings accounts, and changes in household mortgage and nonmortgage debt. Finally, we assessed people's expectations about a large set of behaviors and outcomes going forward, including their expectations about the labor and housing markets, access to credit, their future spending and saving behavior, and expectations for paying down debts.

We found large differences across households in the extent to which they were affected by the recession, especially by income, age, and geography. While considerable proportions of households were not directly affected by declines in the housing, stock, and labor markets, a large share of households were affected by at least one of these. The proportion of households that suffered large declines in housing wealth and in retirement savings, and which experienced large income drops varied across demographic groups, but the proportion that experienced at least one of these was fairly evenly spread across groups.

In response to their deteriorated financial situation, households reduced their average spending. At the same time, they increased their saving, with 
the personal saving rate as measured by the National Income and Product Accounts (NIPA) increasing considerably from historically low prerecession levels. Survey data suggest that if there indeed was a recent increase in household saving, this increase — at least in 2009 — did not materialize through an increase in contributions to retirement and savings accounts. If anything, such contributions actually declined on average during the past year. Instead, the higher saving rate appears to reflect a considerable decline in household debt, particularly mortgage debt. This suggests that rebuilding net wealth was an important driver of household decisions. Unlike the period leading up to the recent recession, during which the average mortgage debt pay-down rate was negative (increases in debt associated with second mortgages, cash-out refinances, and home equity lines of credit exceeded regular principal pay-downs on existing mortgages), since 2008 it has turned positive. Similarly, the steady annual increase in outstanding nonmortgage debt (also referred to as consumer debt) came to a halt in 2009. However, unlike mortgage debt, consumers made little headway in 2009 in actually lowering total nonmortgage debt, with some debt such as that associated with student loans continuing to grow steadily.

Regarding individuals' expectations about the future, we find that individuals across all demographic groups had moderately optimistic expectations about income and earnings in 2010. At the end of 2009, consumers expected to increase spending in 2010 by less than perceived increases in earnings and income, and expected to pay down debt and increase savings, suggesting a shift in attitudes regarding saving and consumption. The implied moderate increase in saving during 2010 is in fact consistent with what we have observed so far in 2010 . While consumers were moderately optimistic about their income prospects, they were pessimistic about the availability of credit, with access to credit expected to become even more difficult during 2010.

\section{Appendix}

\section{The RAND American Life Panel}

The survey data used in this chapter were collected through two survey modules administered over the Internet to participants in RAND's American Life Panel (ALP). The ALP is an Internet panel of respondents age eighteen and over. Respondents in the panel either use their own computer to $\log$ on to the Internet or they were provided a small laptop or a WebTV, which allows them to access the Internet using their television and a telephone line. The technology allows respondents who did not have previous Internet access or a computer to participate in the panel and furthermore use the WebTVs for browsing the Internet or use email. 
The first survey module we analyze, referred to in the chapter as the RAND survey, was designed by Michael Hurd and Susann Rohwedder to evaluate the effects of the financial crisis. The survey was fielded from November 2008 to February 2009, with the vast majority of respondents completing the survey in November 2008. The NYFed survey on saving behavior was fielded between the end of October 2009 and January 2010, with the vast majority again responding in November 2009. Respondents were paid an incentive of about $\$ 20$ per thirty minutes of interviewing. Although respondents were allowed to skip questions, those who tried to do so received a prompt encouraging them to provide an answer.

Most of the participants in both ALP surveys were randomly selected among participants in the Reuters/University of Michigan Survey of Consumers at the University of Michigan's Survey Research Center. An additional group of respondents were recruited through a snowball sample, through referrals of friends and acquaintances. While all ALP members were invited to participate in the RAND survey on the effects of the financial crisis, the NYFed survey on saving behavior was restricted to a subset of newer ALP members - those who participated in the Michigan Survey after December 2006.

A total of 900 ALP participants completed the NYFed survey, while 2,057 members completed the RAND survey. Respondents in the NYFed survey reported an average age of 50.5 , with a median of 51 . In total, 58 percent were female, 66 percent were married or living with a partner, 52 percent had at least a bachelor's degree, 81 percent owned a home, and 89 percent were white. Twenty-one percent lived in one of the five states that experienced the greatest housing bubble and/or bust, which were Arizona, California, Florida, Michigan, and Nevada. The median reported income range was $\$ 60,000-\$ 75,000$, with 43 percent of the respondents reporting incomes over $\$ 75,000$.

Respondents in the RAND survey reported an average age of 50.0, with a median age of 51 . In total, 57 percent were female, 65 percent were married or living with a partner, 45 percent had at least a bachelor's degree, 78 percent owned a home, and 90 percent were white. Twenty-two percent lived in one of the five bubble/bust states. The median reported income range was $\$ 60,000-\$ 75,000$, with 37 percent of the respondents reporting incomes over $\$ 75,000$. For a more detailed description of the sample, see Hurd and Rohwedder (2010).

In all the analyses reported in this chapter, sample weights were applied to make the two samples representative of the US population. The weights were computed to equate sample proportions to those in the 2009 Current Population Survey for all population subgroups defined by homeownership, living in a bubble state, income under $\$ 30,000$, age under forty, and having a college degree. 


\section{The FRBNY Consumer Credit Panel}

Some of the analyses in this study are based on credit report data from the FRBNY Consumer Credit Panel. The panel comprises a nationally representative 5 percent random sample of US individuals with credit files, and all of the household members of those 5 percent. In all, the data set includes files on more than 15 percent of the adult population (age eighteen or older), or approximately 37 million individuals in each quarter from 1999 to the present. The underlying sampling approach ensures that the panel is dynamically updated in each quarter to reflect new entries into and exits out of the credit markets, with young individuals and immigrants entering the sample and deceased individuals and emigrants leaving the sample at the same rate as in the population of individuals with credit files. In each quarter, the records of all other household members who shared a primary individual's mailing address were also included. Even though all individuals included in the database are anonymous, the panel allows one to track individuals and households consistently over time. In addition to the computation of nationally representative estimates of individual and household-level debt and credit in each quarter, the panel therefore permits a rich analysis of the dynamics of consumer debt and related policy issues at both the individual and household levels.

Since the FRBNY Consumer Credit Panel data are collected at the borrower level, they offer a more comprehensive perspective on mortgage debt than is available in standard loan-level data sets. In addition to detailed data on all debts secured by residential real estate, the panel includes information on individuals' and households' other loans, such as credit cards, auto loans, and student loans. More general information available in the panel include the residential location of the borrower at the census block level, the individual's year of birth, the individual's credit experience such as foreclosure, bankruptcy, and collection, as well as a consumer credit score that is comparable to the well known FICO score. More details regarding the sample design and data content can be found in Lee and van der Klaauw $(2010){ }^{23}$

\section{References}

Bruine de Bruin, Wändi, Simon Potter, Robert Rich, Giorgio Topa, and Wilbert van der Klaauw. 2010. "Improving Survey Measures of Household Inflation Expectations." Current Issues in Economics and Finance 16(7). http://www.newyorkfed. org/research/current_issues/ci16-7.html. 
Brown, Meta, Andrew Haughwout, Donghoon Lee, and Wilbert van der Klaauw. 2010. "The Financial Crisis at the Kitchen Table: Trends in Household Debt and Credit." Staff Report no. 480, Federal Reserve Bank of New York, December.

Bucks, Brian K., Kennickell, Arthur B., Mach, Traci L., and Kevin B. Moore. "Changes in US Family Finances from 2004 to 2007: Evidence from the Survey of Consumer Finances." Federal Reserve Bulletin, vol. 95, Board of Governors of the Federal Reserve System. February.

Haughwout, Andrew, Richard Peach, and Joseph Tracy. 2010. "The Homeownership Gap." Current Issues in Economics and Finance 16 (5). http://www.newyorkfed.org /research/staff_reports/sr418.html.

Hurd, Michael D., and Susann Rohwedder. 2010. "Effects of the Financial Crisis and Great Recession on American Households.” NBER Working Paper no. 16407, Cambridge, MA.

Lee, Donghoon, and Wilbert van der Klaauw. 2010. "An Introduction to the FRBNY Consumer Credit Panel.” Staff Report no. 479, Federal Reserve Bank of New York, November. 